\title{
EVALUATION OF A COMMUNITY PHARMACIST MANAGED ASTHMA CONSULTATION SERVICE
}

\author{
by \\ John Odame, BSc, Western University, 2015 \\ A thesis \\ presented to Ryerson University \\ in partial fulfillment of the \\ requirements for the degree of \\ Master of Science in Management \\ in the program of \\ Master of Science in Management \\ (Health Management) \\ Toronto, Ontario, Canada, 2019 \\ (C) John Odame, 2019
}




\section{AUTHOR'S DECLARATION FOR ELECTRONIC SUBMISSION OF A THESIS}

I hereby declare that I am the sole author of this thesis. This is a true copy of the thesis, including any required final revisions, as accepted by my examiners.

I authorize Ryerson University to lend this thesis to other institutions or individuals for the purpose of scholarly research.

I further authorize Ryerson University to reproduce this thesis by photocopying or by other means, in total or in part, at the request of other institutions or individuals for the purpose of scholarly research.

I understand that my thesis may be made electronically available to the public. 


\section{Abstract}

Evaluation Of A Community Pharmacist Managed Asthma Consultation Service, Master of Science in Management (Health Management)

Ryerson University

2019

John Odame

Background: Asthma is one of the most common chronic health conditions, affecting 900,000 Ontarians and 2.4 million Canadians. Research evidence indicates that pharmacists can play a critical role in the management of asthma yet there is a paucity of studies which focus on community-based pharmacist asthma interventions on adults in Ontario, Canada.

Purpose: The aim of this study is to evaluate an asthma-specific pharmacist-led intervention over a 12-month period in relation to patient health outcomes and patient satisfaction.

Methods: This prospective cluster randomized controlled study required trained intervention pharmacists to identify asthma patients, deliver medication reviews and educate patients in order to improve asthma measures. The validated measures selected for the study were adherence to medication, asthma knowledge and peak expiratory flow rate. 12 pharmacies in and around Toronto, Ontario were recruited.

Results: A total of 81 patients were identified by pharmacists as potential participants over the course of the program. Of these, 19 consented to participate and 14 completed the program. The intervention group saw a statistically significant improvement of asthma knowledge scores $(\mathrm{p}=0.02)$. In both groups, all patients had improved medical adherence scores after completion of the program. Diurnal variation between control and intervention groups was found to be significantly different. Control patients had significantly more days of high variability than the intervention group.

Conclusion: The implementation of a pharmacist-provided comprehensive education program in a community pharmacy setting had a positive impact on patients' diurnal variation, asthmarelated knowledge and adherence to medication. While the target sample size was not achieved and results cannot be generalized, this study is an important step towards understanding the benefits of a pharmacist-delivered intervention in asthma management. 


\section{Acknowledgements}

I would like to express my appreciation to the study sponsors, including GlaxoSmithKline and AstraZeneca and Ontario Pharmacist Association. I would like to thank all of the pharmacists and patients and that participated in this study as well as the following pharmacies: Shoppers Drug Mart, Lovell Drugs, Guardian Pharmacy, Procare Pharmacy, Wellness Health Pharmacy, Apple Hills Pharmacy and Pharmacy 101 for facilitating their pharmacists involvement in the study.

I would like to thank Dr. Pria Nippak, Associate Professor Ryerson University and Dr. Zahava Rosenberg-Yunger, Adjunct Professor Ryerson University and Lee Verweel for the supervision and assistance throughout this project. 


\section{Table of Contents}

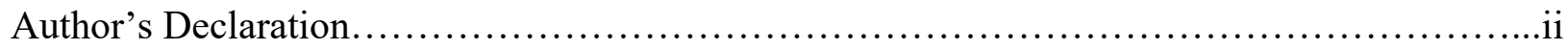

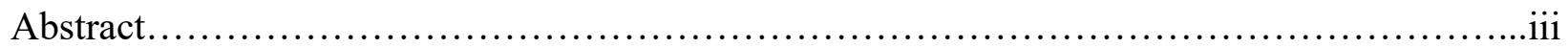

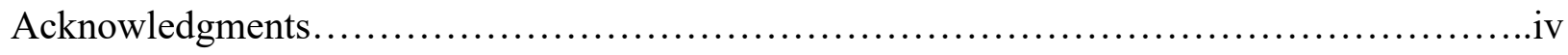

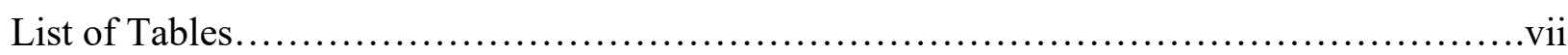

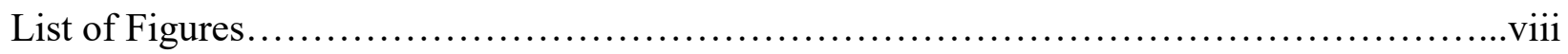

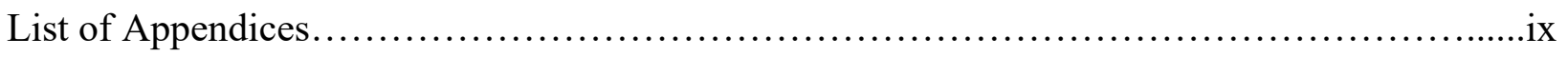

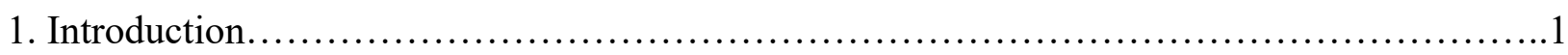

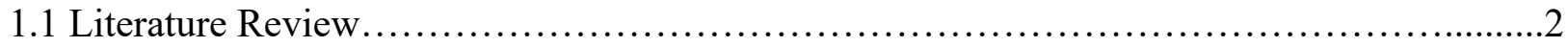

1.1.1 Pulmonary Function........................................................

1.1.2 Compliance and Adherence................................................. 4

1.1.3 Asthma Knowledge............................................................

1.1.4 Literature Review Summary ...............................................

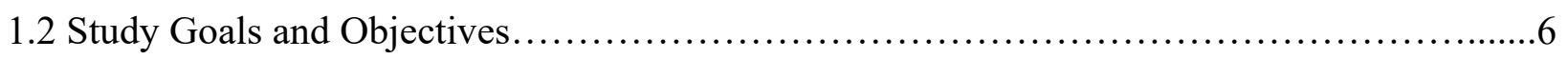

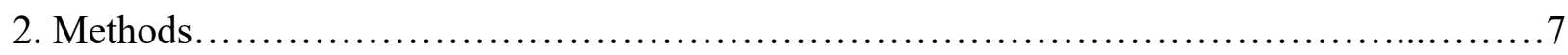

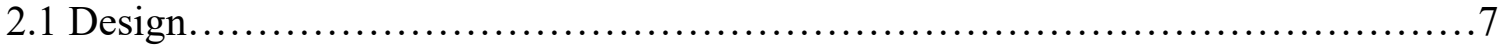

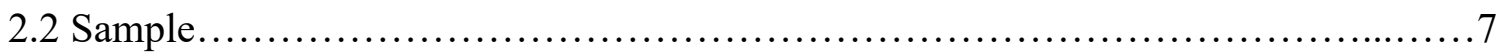

2.2.1 Inclusion/Exclusion Criteria......................................... 8

2.2.2 Research Ethics..................................................

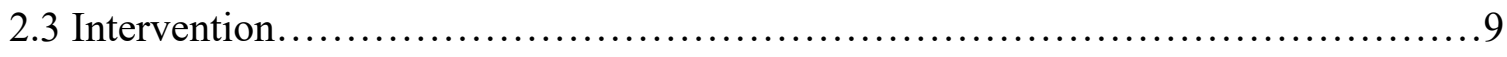

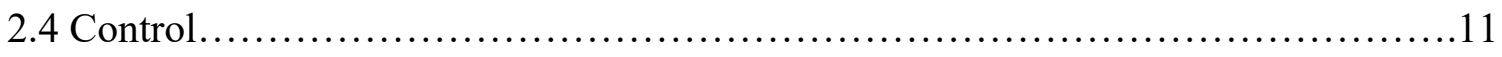

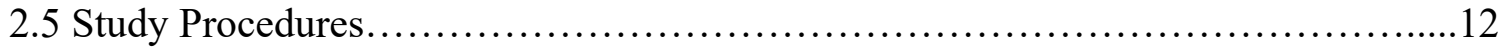

2.6 Patient Questionnaires.......................................................

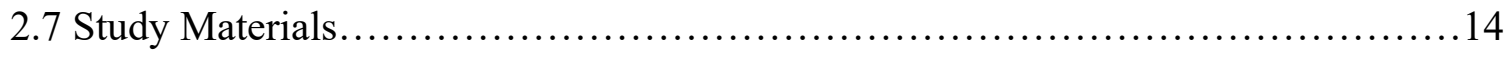

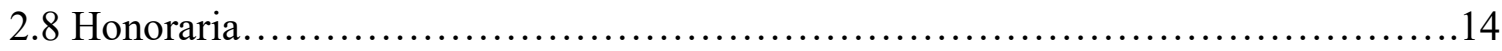

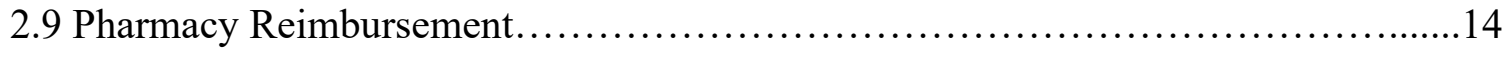

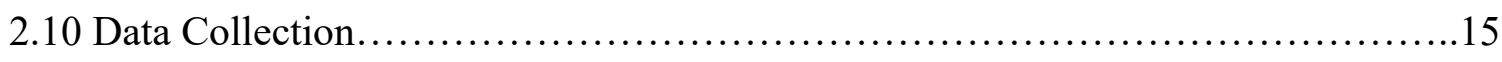

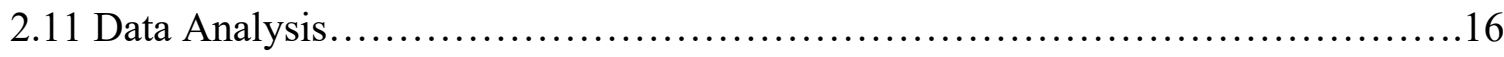


2.11.1 Asthma Knowledge................................................16

2.11.2 Medical Adherence.................................................16

2.11.3 Peak Expiratory Flow Rate........................................ 16

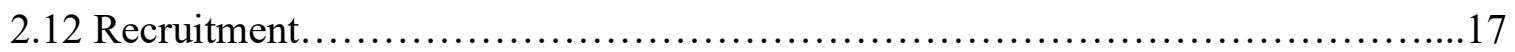

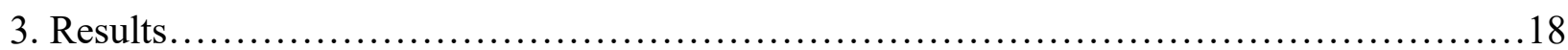

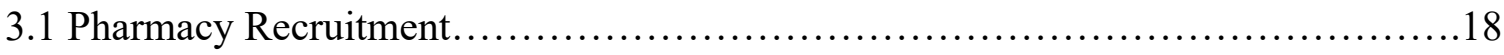

3.2 Patient Recruitment Results.....................................................19

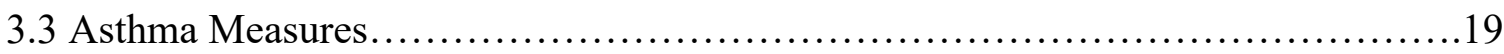

3.3.1 Asthma Knowledge.................................................. 19

3.3.2 Medical Adherence..................................................20

3.3.3 Peak Expiratory Flow Rate............................................20

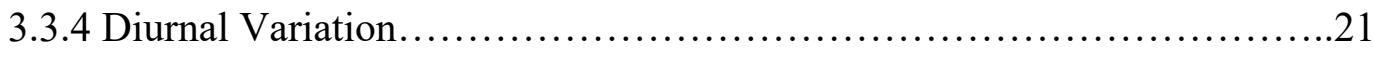

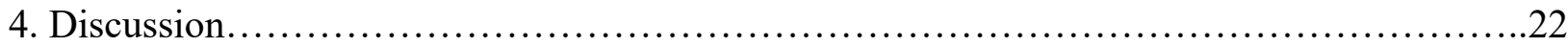

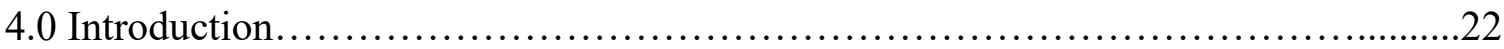

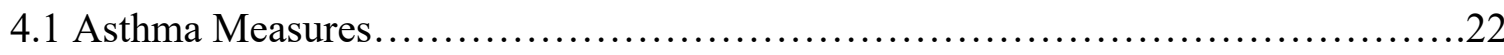

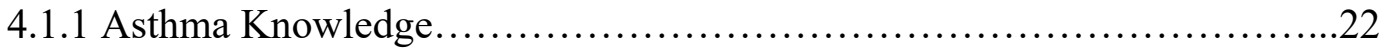

4.1.2 Medical Adherence................................................23

4.1.3 Peak Expiratory Flow Rate...........................................24

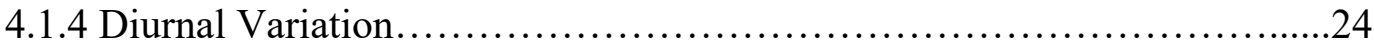

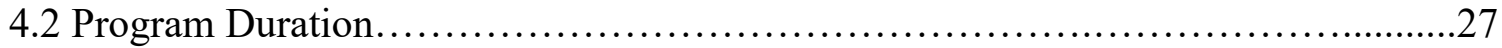

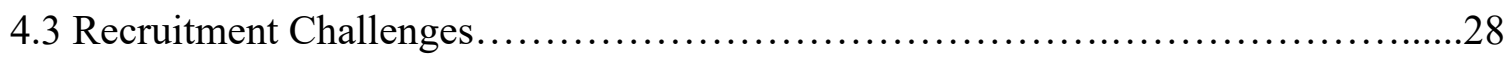

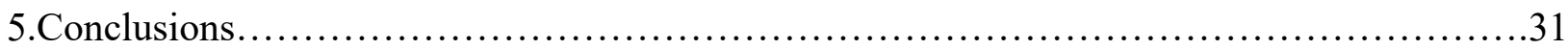

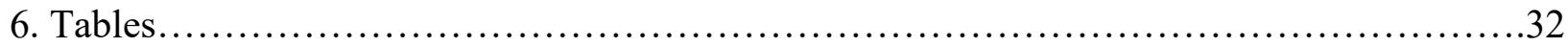

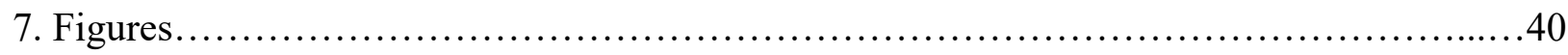

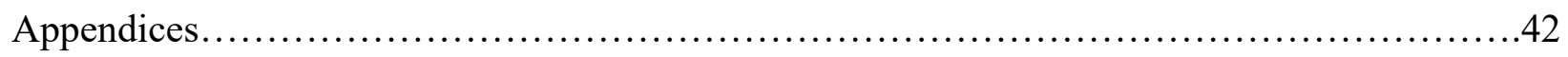

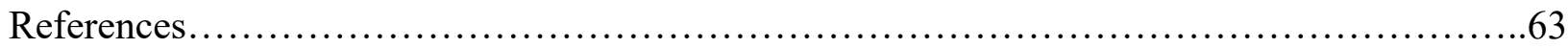




\section{List of Tables}

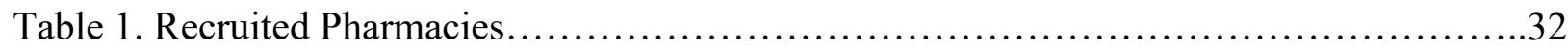

Table 2. Study Procedures and Measures............................................. 33

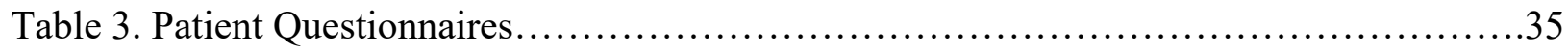

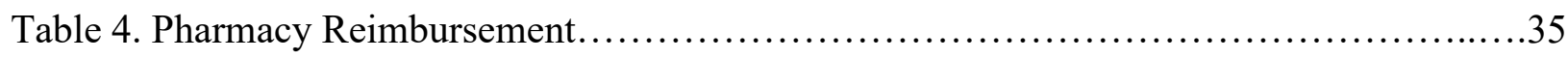

Table 5. Amplitude Mean $\%$ Calculation............................................ 36

Table 6. Pharmacist Demographic Results........................................ 36

Table 7. Mean and Standard Deviation of Asthma Measure Scores...........................37

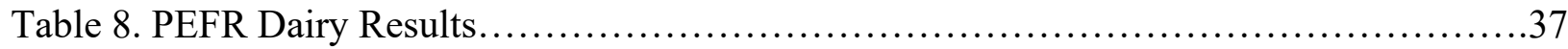

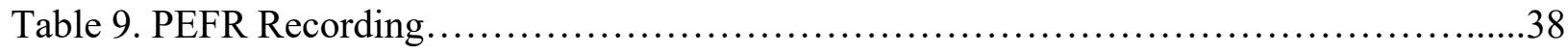

Table 10. High Diurnal Variation of PEFR ............................................ 38

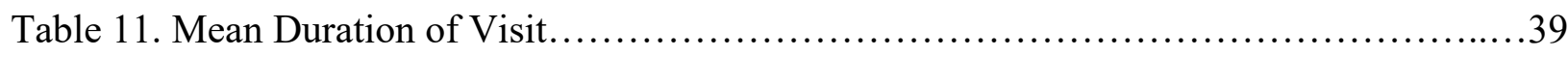

Table 12. Study Completion Duration of each Patient....................................39 


\section{List of Figures}

Figure 1. Total Consented Identified and Declined as of December 2017..................40

Figure 2. Recruitment Challenges and Modifications .................................40 


\section{List of Appendices}

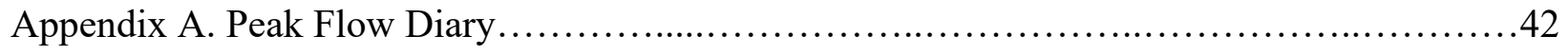

Appendix B. Medication Adherence Report Scale for Asthma (MARS-A) ...................43

Appendix C. Asthma General Knowledge Questionnaire for Adults........................44

Appendix D. Study Services Agreement........................................... 46

Appendix E. Pharmacist Demographic Questionnaire ................................55

Appendix F. Patient Demographic Questionnaire......................................54

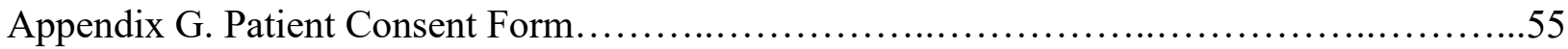

Appendix H. Asthma-Specific Data Collection Form.................................6 60

Appendix I. Asthma Poster.......................................................62 


\section{Introduction}

Asthma is one of the most common chronic health conditions, affecting 900,000 Ontarians, 2.4 million Canadians and over 300 million people worldwide (Ontario Lung Association, 2016). It is characterized by recurrent episodes of airway obstruction, which reverse either spontaneously or after use of medication (Center, 2013). Though asthma is generally considered a chronic disease, it can be fatal in some instances - approximately 250 people die each year from asthma in Canada (Hermus, 2012). Effective management of this chronic condition has been shown to prevent exacerbations and more severe negative health consequences. Estimates show that over $80 \%$ of the asthma-related deaths could be prevented through proper education. Evidence also shows that over 55\% of patients with moderate to severe asthma do not have their asthma symptoms under control, despite regular doctor visits (Peters, 2007). Less than a third (31\%) of asthma patients report receiving an asthma action plan from their physicians, although such plans are associated with fewer emergency room (ER) visits, lower hospitalization rates and improved lung function (Public Health Agency of Canada, 2007). Hence, there is a clear opportunity to improve the management of asthma and reduce the incidence of related complications (National Institutes of Health, 1995).

There has been an increasing recognition that pharmacists are an underutilized resource when it comes to chronic disease management (Ontario Pharmacists Association, 2014). This recognition is partially due to the evolution of pharmacy practice from a product-oriented service to a holistic patient-oriented service. Since the 1990's, pharmacists in Canada and internationally have embraced a philosophy of practice termed pharmaceutical care (Helper, 1990). Through the provision of pharmaceutical care, pharmacists have played a greater role in the management of patients' chronic diseases. In particular, they have been involved in 
educating patients, improving adherence to drug therapy, monitoring patients' conditions and optimizing drug therapy in collaboration with patients' prescribers (Lee, 2012). More recently, pharmacists in Ontario have been granted an expanded scope of practice that includes the authority to independently adapt and renew prescriptions for chronic conditions (Ontario College of Pharmacists, 2013). Utilizing this expanded scope of practice, pharmacists are better equipped to proactively optimize patient medication therapy, improve adherence and continuity of care.

The increasing of pharmacist utilization can be a key component in improving asthma management and reducing the incidence of related complications. Implementation of a pharmacist-delivered program for asthma can give pharmacists the opportunity to improve effective use of medicines and provide education about medicines. In Canada, there have only been a few studies conducted on the impact of pharmacy-based interventions on asthma specifically on adults.

\subsection{Literature Review}

There is a growing body of evidence indicating pharmacists' ability to play a critical role in the management of asthma. Two systematic reviews of pharmacist interventions in asthma management have demonstrated significant improvements in clinical, and economic outcomes (McLean, 2005; Lemmens, 2009). A study conducted in British Columbia showed that pharmacist interventions related to asthma over a 1-year time period improved the peak expiratory flow rate and health-related quality of life (McLean, 2003). In addition, this intervention led to a decrease in overall health care costs, including a decrease in emergency department visits and outpatient physician visits. Other studies have also shown significant improvements in asthma knowledge and adherence to medication therapy (Saini, 2011; Mehyus, 
2008; Armour, 2007). These studies demonstrate that pharmacist interventions can significantly improve patients' clinical outcomes in asthma and that such improvements translate into health system savings (Sadatsafavi, 2010). The literature on pharmacists led interventions in in asthma management focus on the following areas; pulmonary function, compliance and adherence and asthma knowledge. A summary of the literature in these areas of focus are detailed below.

\subsubsection{Pulmonary Function}

Many studies indicate the effect of interventions on specific patient outcome measures such as pulmonary function, which is measured by peak flow expiratory flow rate and forced expiratory volume (FEV1). Peak expiratory flow rate (PEFR), refers to the maximum rate of airflow during exhalation. The major determinants of the PEFR are the force of contraction of the expiratory muscles, the recoil forces of the lungs and chest wall, and large airway resistance (Cross, 1991).

Recording of PEFR is useful for controlling asthma by demonstrating the variable airflow limitations that characterize the disorder. Peak flow meters quantify the potential airway obstruction by measuring the rate of the peak expiratory flow (PEFR) (Willems, 2006).

Peak expiratory flow rates (PEFR) measured under the supervision of the pharmacist improved significantly over a 12-month period (Schulz, 2001). In one of the largest studies in community pharmacies done in Canada, pharmacist interventions related to asthma across a 1year time period improved peak expiratory flow rate (McLean, 2003). In addition, the intervention led to a decrease in overall health care costs, including a decrease in emergency department visits and outpatient physician visits.

PEFRs measured repeatedly over a period and plotted against time results in a graph that can help to expose features of a patient's asthma condition. Daily measurements using a peak 
flow meter have been used to identify triggers for asthma exacerbation and declines in pulmonary function and these are important factors for health professionals treating asthmatics (Knobloch, 2013).

It has been suggested that individuals with suboptimal asthma control have exaggerated diurnal changes in airway size and daily PEFR measurements can observe these significant variations (Knobloch, 2013). Declines in PEFR and increasing variability of PEFR can be a predictor of worsening of pulmonary function and improvement of asthma control has also been associated with decreases in diurnal variability (Pierce et al, 1995). Jamison (1993) concluded that numerical indices of peak flow variability are highly valid tests for asthma and diurnal variations greater than 20\% have been used to diagnose asthma (Aggarwal, 2000).

\subsubsection{Compliance and Adherence}

Adherence to asthma therapy is essential to maximize its therapeutic benefit and minimize exacerbations. Survey data demonstrated that few patients measure peak flow daily and this reduced adherence has an impact on hospitalization and emergency department visits (Legorreta, 1998).

Most patients with severe to moderate asthma were not interested in measuring peak expiration force rate (PEFR) twice daily over a prolonged period of time (Cote, 1998). Cote (1998) also saw $60 \%$ of the subjects in his study measuring their PEFR less than $25 \%$ of the time after 12 months. This represents a challenge for engaging asthma patients in properly taking daily PEFR measurements.

A randomized clinical trial conducted in community pharmacist in Northern Ireland in which compliance was self-reported, a higher portion of intervention patients were compliant with their medication at 12 and 18 months compared to control patients (Sturgess, 2003). 
A 6-month randomized control trial study conducted in 66 community pharmacies also found adherence to their inhaler medication to be significantly higher in the intervention group (Mehuys, 2008). Mehuys (2008) also assessed adherence with self-reported scores and prescription refills rates, both of which were validated measures.

\subsubsection{Asthma Knowledge}

Asthma is a disease in which knowledge of the nature of symptoms and awareness of the trigger factors for exacerbations can help to improve asthma control and adherence to therapy (Saini, 2011). Patients who visited their pharmacy three to four times over a six-month period to receive educational interventions saw improvements in their asthma knowledge scores (Saini, 2011). In this study, a 12-item true/false validated questionnaire known as the Consumer Asthma Knowledge Questionnaire was used to measures asthma knowledge. Saini chose this questionnaire as opposed to the Asthma General Knowledge Questionnaire for Adults (AGKQA) due to its more recent validation in 2005.

Saini (2011) speculated the implementation of a more intensive pharmacy-based services could result in retention of asthma knowledge for at least 12 months (Saini, 2011).

Another study demonstrated improved asthma knowledge as well as patient attitudes to asthma as a disease (Narhi, 2001). This study showed the power of structured training by a pharmacist on both patient adherence and patient attitudes toward their condition. The results of these studies indicate that pharmacy-based services are capable of improving asthma knowledge. 


\subsubsection{Literature Review Summary}

The studies described above demonstrate the role pharmacists can play in the improvement of patients' clinical outcomes in asthma through the implementation of appropriate interventions. Due to the chronic nature of asthma, the targeting of the outcomes such as those discussed above is critical in attempting to manage the condition and improve overall quality of life of the patient. Pharmacists are uniquely positioned both in regards to the nature and frequency of intervention delivery. Pharmacists have been able to deliver interventions that improved patients' knowledge of their condition, their use of instruments to measure their lung function and asthma quality of life (McLean, 2003). Moreover, through educational interventions, pharmacists have been able to communicate the importance of adherence to medication and asthmas knowledge and these are vital components to avoiding exacerbations and controlling asthma related symptoms (Schulz, 2001). Improvements to the outcome measures addressed in this literature review also translate into significantly lower utilization of health care resources (Sadatsafavi, 2010).

\subsection{Study Goals and Objectives}

Given the scientific evidence of pharmacists' effect on asthma management there is a strong rationale for introducing an asthma-specific pharmacist-led intervention in Ontario. The Ontario Pharmacists Association believes the implementation of such a program should be preceded by a pilot test to ensure that the program parameters are optimized to drive improved patient outcomes and maximum quality of service. The gap in knowledge identified by the Ontario Pharmacists Association led to the conducting of this asthma consultation service.

Results from a study of this nature may assist decision making on asthma treatment selection and management guidelines in Canada and will provide valuable insight for others in 
the field. The goals of this research project, which are part of a larger research study conducted by Ontario Pharmacists Association, are to examine the impact of a pharmacist led asthma management intervention on the following asthma related health outcomes: Peak expiratory flow rate, asthma related knowledge and adherence to medication.

We also aimed to follow asthma patients for approximately a year to distinguish the study design from other Canadian studies as only select few have gathered data past 6 months from baseline. We believed lengthening the follow up time from baseline can be important specifically when analyzing medication adherence of the asthma patients. Since compliance to medication as an asthmatic patient is necessary, the knowledge or awareness of fundamental facts about the treatment must be analyzed in order to reduce non-compliance rates.

Through the analysis of multiple outcome measures, we aimed to bring awareness to areas that are needing of improvement for both patient outcomes and for strategizing the implementation of educational interventions.

\section{Methods}

\subsection{Design}

This pilot study consisted of a prospective, randomized controlled trial conducted in the community setting. The study began on May $1^{\text {st }}, 2016$ and recruitment ended on April $1^{\text {st }}, 2017$.

\subsection{Sample}

A total of 12 pharmacies across the Greater Toronto Region were recruited for this study. Recruited pharmacies were randomly assigned in a 1:1 ratio to either the intervention 
group or the control group. The randomization was conducted at the pharmacy level, in order to avoid contamination at the patient level and to ensure only the intervention group patients received pharmacists' intervention. This allowed for causal conclusions to be drawn regarding the effect of pharmacist intervention on patient outcomes.

During the pharmacy recruiting process, a conscious effort was made to ensure each pharmacy recruited had a matching partner based on their pharmacy ownership. Therefore, all independent, banner, franchise and chain pharmacies recruited were matched with a pharmacy of the same ownership (Table 1). This was done to eliminate the possibility of differences between pharmacy ownerships affecting results.

Both patients and pharmacists were not blinded with respect to their group assignment. Due to the design of the program, pharmacists needed to be privy to their assigned group and their tasks required based on their group. All pharmacists recruited completed a demographic questionnaire before the commencement of the program (Appendix E).

\subsubsection{Inclusion/Exclusion Criteria}

To be enrolled in the program, each patient was required to be intending to refill all asthmarelated prescriptions at the study pharmacy, diagnosed with asthma by a physician or nurse practitioner, taking inhaled corticosteroids for which the dose and/or medication remained unchanged for at least 2 months and 18 years of age or older.

Patients were also required to have uncontrolled asthma, which was defined by the use of 4 or more rescue medications within a given week in the past month and/or asthma symptoms that have woken the patient up from sleep at least once within a given week in the past 4 weeks.

Patients were not to be enrolled if they were unable or unwilling to return to the pharmacy for scheduled visits, unable to speak English language well enough to communicate with the 
pharmacist and complete the questionnaires independently, terminal ill, had a history of alcoholism or drug abuse, or any of the following comorbidities/health issue : chronic obstructive pulmonary disorder (emphysema; chronic bronchitis), acute respiratory infection, pulmonary fibrosis, cancer (in the past 5 years preceding enrolment), organ transplantation dementia, cognitive impairment or other psychiatric disorder, any other health issue that may hinder performance on pulmonary function test, enrolled in an Employee Assistance Program for disease management within 6 months preceding the study enrolment date or planning to enroll in the next 12 months, enrolled in another asthma management/clinical study or planning to enroll in a similar study in the next 12 months, had a MedsCheck or MedsCheck Follow-Up done within the 3-month period preceding the anticipated date of the first study appointment, patients who do not wish their physician to be notified of their participation.

\subsubsection{Research Ethics}

This study was approved by Ryerson University’s Research Ethics Board (2015-370). Precautions were taken to protect patient confidentiality and anonymity including encryption and password protection of files. The form linking participant names to their identifiers was stored separately in a locked filing cabinet. Only the research team (supervisors, research coordinators and graduate student) had access to the master lists of study participants.

\subsection{Intervention}

Pharmacists in the intervention group provided patients with a comprehensive disease management program for asthma. The three major components of pharmacists' intervention are medication review and drug therapy optimization, patient education and improving patient adherence. The services delivered were customized based on each patient's case. 


\section{Medication review and drug therapy optimization}

Pharmacists comprehensively reviewed patient's medication therapy focusing on potential interactions, suboptimal dosages and adherence issues as related to their asthma.

The pharmacist developed an individualized medication plan which was to be shared with the patient's primary care provider via fax. If necessary, the pharmacist conducted a medication review follow-up to address any outstanding drug therapy-related issues.

\section{Patient education}

Based on each patient's case, pharmacists provided education/counseling on basic pathophysiology of asthma, proper device usage technique, recognition and avoidance of trigger, symptom management techniques, smoking cessation, appropriate use of relievers (rescue medications) and controllers (preventative medications), self-management skills including monitoring of peak flow, action in response to worsening symptom, and how to access emergency care appropriately.

\section{Improving patient adherence}

Pharmacists utilized evidence-based strategies to improve patient adherence to medication therapy (Atreja, 2005). The following six strategies, summarized by the acronym "SIMPLE", were utilized: Simplifying regimen characteristics - for example switching to a drug that can be taken once a day instead of twice a day. Imparting knowledge - by ensuring patients understand the purpose of their medications. Modifying patient beliefs about the negative effects of non-adherence and the positive effects of treatment. Patient communication improvement by involving patients in decision-making and communicating in 
language the patient understands. Leaving the bias and not basing interventions on demographic factors such as gender. Evaluating adherence by measuring and evaluating patient adherence reliably.

In order to deliver the service outlined above, intervention group pharmacists completed a 7-hour training/orientation program developed by the Ontario Pharmacists Association's continuing Professional Development department. A Respiratory Therapist was invited to educate pharmacists on asthma treatment and management topics. Pharmacists in the intervention group were trained on patient identification procedure, peak flow meter use, asthma guidelines and treatment, lifestyle counseling and education, strategies to improve adherence to medication therapy and data recording (paper-based forms).

\subsection{Control}

Pharmacists were instructed to deliver standard dispensing services to all control group patients in accordance with standards of practice adopted by the Ontario College of Pharmacists (National Association of Pharmacy Regulatory Authorities, 2010).

Prior to recruitment, control group pharmacists completed a 4-hour training/orientation developed by the Ontario Pharmacists Association's continuing Professional Development department. Pharmacists in the control group were only trained on patient recruitment and enrolment procedures, peak flow meter use and data recording (paper-based forms).

Control pharmacists did not voluntarily offer the three intervention components outlined above. If a control group patient requested additional information and/or services, the pharmacist complied and provided these as deemed necessary for the particular patient. Control group pharmacists did not receive full training therefore only standard dispensing services could be 
delivered to patients. Control pharmacists were to distribute educational handouts at the end of the study.

\subsection{Study Procedures}

Table 2 outlines the study procedures. The study investigators were in contact with the pharmacies regularly throughout the study period. The investigators checked with the study pharmacies by phone or in person at regular intervals throughout the patient enrolment period to encourage and assist recruitment progress. Pharmacist feedback and study investigators preferences were used to determine the length of the recruitment period. Following their enrollment in the study, patients met with their pharmacist for a maximum of eight appointments ( 1 baseline, 1 final and 6 interim visits). All appointments took place in-person at the pharmacy.

\subsection{Patient Questionnaires}

Table 2 outlines when each questionnaire was distributed. Permission to use all copyrighted questionnaires was obtained.

Peak expiratory flow rate was measured using the Peak Flow Diary Form (Appendix A). This form allows patients to record their PEFR on a daily basis. Daily recording of PEFR was chosen due to its ability to identify triggers for asthma exacerbation and declines in pulmonary function, both of which are important factors for health professionals treating asthmatics (Knobloch, 2013).

Given that pharmacists' have a role in the improvement of the pulmonary function of asthma patients, the monitoring of peak expiratory flow rate over time may produce valuable data for assessing the effectiveness of asthma interventions. 
Given that pharmacists' within the study had a role to improve asthma knowledge for patients, the Asthma General Knowledge Questionnaire for Adults (AGKQA) was used to collect data on this outcome (Allen, 1998). AGKQA is a 31-item questionnaire that has demonstrated to be a valid and reliable measure for assessing knowledge relevant to adult selfmanagement.

This True and False questionnaire was designed to test both asthma educators and asthmatic patients enrolled in a self-management education program. Items in the questionnaire include asthma pathophysiology, medication, assessment of severity and symptom management. (Allen, 1998). AGKQA is straight forward to administer and scoring of the questionnaire is simply the number of correct items out of the 31 . A higher number of correct answers indicates greater asthma knowledge.

Given that pharmacists' have a role in the improvement of patient adherence to asthma therapy, adherence was measured using the Medication Adherence Report Scale for Asthma (MARS-A) (Appendix B). MARS-A is a 10-item questionnaire that has demonstrated to be a valid and reliable measure for assessing adherence to medication (Cohen, 2009).

The MARS-A questionnaire is a modified version of a Medication Adherence Report Scale (MARS) questionnaire which is one of the most widely used adherence rating scales (Thompson, 2000). Respondents indicate their agreement with 10 statements about their medicine use on a 5 point Likert scale and this gives pharmacists or other health professionals an estimate of a patient's adherence behavior. 


\subsection{Study Materials}

During the pharmacist training session that occurred prior to patient recruitment, a binder with study materials was given to all pharmacists. Twelve peak flow meters, which were donated by MacArthur Medical Sales Inc., were given to each pharmacy for each potential asthma patient. Pharmacies also received weighing scales (if pharmacy did not already have one that could be used), an asthma information flyer (Appendix I), paper forms of questionnaires for distribution to patients (Table $2,3^{\text {rd }}$ column) and a copy of the study procedures.

\subsection{Honoraria}

Patients enrolled in the study received a \$10 Tim Hortons gift card after completing the baseline, $3^{\text {rd }}$ and $6^{\text {th }}$ interim visits. Patients also received a $\$ 20$ honorarium after the research team received their completed patient satisfaction questionnaires.

The individual pharmacists part of the intervention group participating in this study received honoraria for completing the 8-hour training program $(\$ 360)$, enrolling the requisite number of patients (\$125) and completing the exit interview (\$40). Control pharmacists received honoraria for completing the 4-hour training program $(\$ 180)$ and enrolling the requisite number of patients $(\$ 125)$.

\subsection{Pharmacy Reimbursement}

Table 4 outlines the pharmacy reimbursement schedule. The pharmacies participating in this study were compensated on a fee-for-service basis. Claims were manually submitted to the study investigators except in cases where the patient that was eligible for the MedsCheck program. MedsCheck Annual is a free one on one medication review offered by community pharmacists to patients and all Ontarians taking three or more prescription medications. MedsCheck Follow-up 
is the follow-up review service developed for patients who have already had an annual review and require more service due to complexities of their drug regimen.

Both MedsCheck programs are paid for by the Ontario Government through the Ontario Drug Benefit Program (ODB) Health Network System therefore MedsCheck and MedsCheck Follow-Up claims were billed to the Ontario Public Drug Programs Branch (Ministry of Health and Long-Term Care, 2010). For patients that were not eligible for a MedsCheck due to having already had one in the past year or because they are taking fewer than 3 medications, the claims were to be submitted directly to study investigators.

In addition, pharmacists were compensated an additional $\$ 15$ for each MedsCheck provided (on top of the current $\$ 60$ reimbursed through MedsCheck Annual).

\subsection{Data Collection}

Patient data was collected during their interactions with their pharmacist. All data was written on paper. The pharmacist retained the paper copies of all questionnaires and peak flow diaries completed by the patient. A research assistant visited each of the pharmacies participating in the study to collect all of the data including copies of questionnaires, patient medication profiles and all of the pharmacist-completed data collection forms. In one case, a pharmacist mailed the completed questionnaire forms to the research team with prior approval from the REB. After data retrieval from each pharmacy, all data was then entered into an Excel spreadsheet for analysis. 


\subsection{Data Analysis}

All paper records were converted to a password protected Excel database then into SPSS for Windows 8.0 for statistical analysis. Significance level was set at 0.05 and p values less than 0.05 were considered statistically significant.

\section{Asthma Knowledge}

To measure asthma knowledge, the Asthma General Knowledge Questionnaire for Adults (AGKQA) was given to all study patients at their baseline and final visit. Changes between baseline and final visit were compared within groups using paired t-tests. Shapiro Wilk and Q-Q plots were used as tests to meet assumptions of normality for t-test. Patient data was omitted from within group analysis if baseline or final visit values were missing.

\section{Medical Adherence}

The asthma patients' medical adherence to inhaled corticosteroids (ICS) was measured at baseline and final visit by a self-reported 10-item questionnaire known as Medication Adherence Report Scale for Asthma (MARS-A). Patients who reported scores of over 4.5 were classified as patients who highly adhered to their ICS medication (Cohen, 2009). Changes between baseline and final visit were compared within groups using paired t-tests. Shapiro Wilk and Q-Q plots were used as tests to meet assumptions of normality for t-test. Patient data was omitted from within group analysis if baseline or final visit values were missing.

\section{Peak Expiratory Flow Rate}

In order to quantify the fluctuations in peak flow, analysis on peak flow was done using amplitude percentage mean. Diurnal variation in PEFR for each patient was calculated using 
amplitude percentage mean $(\mathrm{A} \% \mathrm{M})$ formula below. $\mathrm{A} \% \mathrm{M}$ could not be calculated if a patient did not have a morning or evening peak flow value for any day.

$\mathrm{A} \% \mathrm{M}=$ [ Highest PEFR of Morning or Evening - Lowest PEFRs of Morning \& Evening $]$

[Mean of Highest Morning and Evening Values]

An example of the calculation is provided in Table 5.

A missed peak flow recording of morning or evening represented a half day of missed peak flow. In instances were patient peak flow diary recordings could not be verified due to unreadable values or dates, PEFR values were omitted and not stored in the database.

\subsection{Recruitment}

\section{Pharmacies}

All pharmacies (including chain, franchise, independent) were identified and contacted via email through the Ontario Pharmacists Association's listserv. A research student and research assistant recruited all pharmacies. A targeted e-blast was sent to over 500 pharmacists and pharmacy owner about the program of which a majority were Ontario Pharmacist Association members. A research team member then called approximately 300 pharmacists and pharmacy owners to inform them about the study. Service agreements were then sent via e-mail to pharmacists and pharmacy owners interested in the program (Appendix D).

\section{Patients}


Pharmacists in each of the intervention and control groups identified patients for participation in this study utilizing the procedures outlined below. Each pharmacy was given approximately one year to recruit the requisite number of patients. When a patient came in for a refill of an inhaled corticosteroid medication, the pharmacist informed him/her of the study and determined whether he/she was interested in participating. If the patient expressed interest, the pharmacist assessed the patient for eligibility. The pharmacist then provided details of the study to the patient and asked him/her for their contact information (i.e., phone number and/or email). The pharmacist also screened their pharmacy records for patients who had at least 1 asthmarelated medication dispensed in the previous 6-month period. The pharmacist called or spoke to these patients when picking up a prescription to gauge their interest in participating in the study. If interested, patients were asked for their contact information which was given to the research team to follow up with additional study details. This was done to ensure patients were not coerced, misinformed of program protocol nor influenced by their patient-pharmacist relationship. Following their enrollment in the study, patients met with their pharmacist for a maximum of 8 appointments. All appointments took place in-person at the pharmacy.

\section{Results}

\subsection{Pharmacy Recruitment}

By March 2016, 18 pharmacists from 12 pharmacies in the Greater Toronto Region joined our research team. Table 1 outlines the pharmacy ownership and location of the 12 pharmacies recruited. Two pharmacies dropped out of the study at the mid-way point of the program. Pharmacy dropout was due to poor recruitment and an inability to identify potential 
participants. Table 6 outlines the results of the pharmacist demographic survey (Appendix E). Thirteen pharmacists completed the survey; 8 full-time pharmacists, 4 pharmacy owners and 1 part-time pharmacist (10 females, 3 males). Pharmacists that remained in the study completed a demographic form.

\subsection{Patient Recruitment Results}

Recruitment began in June 2016 and closed in April 2017. A total of 81 patients were identified by pharmacists as potential participants over the course of the program. Of the 81,19 consented, 49 declined and 13 were ineligible based on our criteria (Figure 1). The results reported here are based on the 13 patients that completed the eight study visits as of December 2017.

\subsection{Asthma Measures}

\subsubsection{Asthma General Knowledge Questionnaire (AGKQ)}

A patients' knowledge of asthma in an important factor that affects their ability to control their asthma. Through self-management and educational interventions, we predicted an improvement in asthma knowledge over the study duration. Both groups combined $(\mathrm{n}=12)$ saw a significant increase in knowledge scores from baseline to final visit $(p=0.016)$. Knowledge scores in the control group (24.3) were higher at baseline in comparison to the intervention group (20.4). The final knowledge scores for intervention $(n=5)$ and control $(n=7)$ patients were insignificant $(p=0.42)$. There was a statistically significant improvement in knowledge scores within the intervention $(\mathrm{n}=5)$ group as they improved from $20.4 \pm 1.14$ to $25.00 \pm 2.12\left(\mathrm{t}_{4}=-3.57\right.$, $p=0.02$ ), an improvement of 4.60 . There was not a statistically significant improvement in 
knowledge scores within the control group as they went from $24.3 \pm 3.20$ to $25.7 \pm 1.11 \mathrm{t}_{6}=-$ $1.179, \mathrm{p}>0.05) ;$ an improvement of 0.9. Results are outlined in Table 7.

\subsubsection{Medication Adherence Report Scale for Asthma (MARS-A)}

All patients $(\mathrm{n}=11)$ showed an improvement in their MARS-A score from baseline to final visit and $60 \%$ completed the study with a score greater than $4.5(n=10)$. Patient data was omitted from within group analysis if baseline or final visit values were missing. MARS-A scores of over 4.5 was used to classify patients who highly adhered to their ICS medication (Cohen, 2009). Three intervention group patients scored higher than 4.5 at the final visit. One hundred percent of the intervention group patients finished the program with a score of greater than $4.5 \mathrm{vs} 42 \%$ in the control group. There was an increase in the intervention group as they went from $4.03 \pm 0.70$ to $4.93 \pm 0.11$, an increase of 0.90 following the intervention program however, it was not statistically significant $\left(\mathrm{t}_{2}=-2.59, \mathrm{p}>0.05\right)$. There was a statistically significant improvement in MARS-A scores from 3.34 \pm 0.84 to $4.07 \pm 0.72$ following the control program $(n=7)$; an increase 0.73 following the control program $\left(t_{6}=-3.25 p=0.017\right)$. Results are outlined in Table 7.

\subsubsection{Peak Expiratory Flow Rate}

Table 8 and Table 9 outline the peak expiratory flow rate results of intervention and control patients. Over a 12-month period, the mean total number of peak flow recorded days was greater in the control group than the intervention group. The intervention group had $299 \pm 41$ days of peak flow verses $253 \pm 135$ days for the control group. 
The percentage of days missed of peak flow recording of the total number of peak flow data points ranged from $2 \%$ to $71 \%$ across both conditions. The intervention group averaged $33 \% \pm 29$ vs $17 \pm 20$ in the control group. These results show control patients recorded their peak flow more and missed less days of recording.

The longest number of consecutive days each patient missed recording their peak flow in their dairy was calculated. The intervention group had an average of 21 days for their longest consecutive days missed of peak flow recordings verses 31 days for one of the control group patients (Table 9). The intervention group also missed twice as many peak flow days relative to the control group. Standard deviation of PEFR was lower in the intervention group (20.60) compared to the control group (35.01).

\subsubsection{Diurnal Variation}

Table 10 shows the results of the number of days each patient had an amplitude percentage mean of greater than $20 \%$, an index of diurnal variability. Control patients had significantly more days of high variability than the intervention group. Only one intervention patient had more than 1 day of exaggerated airway size and variation above $20 \%$. The median number of days of PEFR variability over $20 \%$ was 0 days for the intervention group verses 7 days for the control group. Eighty percent of patients in the intervention group had no days of high diurnal variation verses only $11 \%$ for the control group.

These results show high daily peak flow variability was virtually absent in the intervention group and present in the control group. 


\section{Discussion}

\subsection{Introduction}

This section discusses the results of the asthma program and relation of such results to the existing literature of asthma interventions. This section also discusses the challenges faced during the recruitment process and the key learnings that may be valuable for future studies. For clarity, each of the asthma measures discussed has its own subsection. Specifically, asthma measure Peak Expiratory Flow rate is expanded on with the inclusion of the diurnal variation. The duration of program is also discussed as this provides valuable insight for studies that may be conducted in the Greater Toronto Region utilizing a similar design.

\subsection{Asthma Measures}

\subsubsection{Asthma Knowledge}

Asthma knowledge is essential for improving self-management of asthma but increasing knowledge of asthma alone is not sufficient to change behavior. Knowledge must be present for patients to show proper self-management and self-treatment behavior (Van der Palen, 1997).

Pharmacists enrolled in this program provided education on the basic pathophysiology of asthma, proper device usage techniques and symptom management techniques therefore we predicted these services delivered by pharmacists would increase patient asthma knowledge scores over a 12-month period.

Our prediction of improved asthma knowledge scores in the intervention group was correct. The intervention group saw a statistically significant improvement of mean asthma knowledge scores. The increase in knowledge in the control group was also predicted, based on previous studies. Saini (2011) found a sustained increase in knowledge scores over a 12-month 
period using a different asthma knowledge questionnaire. Saini et al. (2011) also concluded that three asthma visits delivered by pharmacists over a six-month service individualized to patient needs can produce significant improvements in asthma knowledge. We predicted, with or without the additional educational services delivered by a pharmacist, increased patient visits to the pharmacy alone would improve asthma knowledge in the community.

Our results proved no statistical improvement from baseline to final visit for asthma knowledge scores in the control group and this emphasizes the importance of targeted educational services for improved asthma knowledge.

\subsubsection{Medical Adherence}

Intervention pharmacists were instructed to deliver evidence-based strategies to improve patient adherence to medication therapy while control pharmacists delivered standard pharmacy services as described in the methods section.

We predicted a greater increase in the Medication Adherence Report Scale for Asthma (MARS-A) scores in the intervention group program relative to the control program. In both groups, all patients had improved MARS-A scores after completion of the program. Scores from the MARS-A were not significantly higher in the intervention group relative to the control group. The increase of mean scores by 0.90 following the intervention although not significant, raised the mean adherence score above 4.5 indicating high adherence in the intervention group. The lack of statistical significance may have been due to the low number of subjects within the intervention group. As predicted, there was a greater increase in mean MARS-A scores in the intervention group.

Despite the lack of significance, the direction of change for the intervention patients 
indicates that the intervention pharmacists had a slight influence on improving patients' adherence to medication.

\subsubsection{Peak Expiratory Flow Rate}

We predicted pharmacist intervention would improve patients' peak expiratory flow monitoring at home due to increased pharmacist reminders, however our results to do not support this hypothesis. Our results showed control patients recorded their peak flow more, missed less days of recording, and also had longer consecutive days of missed peak flow recordings.

We predicted control patients would miss more days of peak flow due to pharmacists not being required to remind and advise patients to record peak flow on their peak flow diary form. The percentage of days missed of peak flow recording of the total number of peak flow data point was almost twice as high in the intervention group. Our prediction of the control group having longer number of consecutive days of missed recordings and higher standard deviation than the intervention group was also correct. Although control patients recorded their peak flow more and missed less days of recording on their peak flow diary, we cannot be certain due to the self-reporting nature of the peak flow diary.

\section{Diurnal Variation}

Although PEFRs were self-reported, they provided valuable information about diurnal variation and evidence of day-to-day fluctuations in the patient's pulmonary function (Aggarwal, 2000). In clinical practice, diurnal variability is rarely used due to the calculations involved and their time consuming nature therefore we predicted study pharmacists would not access this index over the duration of the program. Our analysis of PEFRs after patient completion of the 
program uncovered an unexpected difference between intervention and control patients. An amplitude percentage mean (A\%M) score greater than $20 \%$ was used as the index to classify high variability days of peak flow for each patient. This index has also been used to diagnose asthma (Aggarwal, 2000). All patients enrolled in this study were diagnosed with asthma therefore days of high diurnal variation were expected across all patients yet our results showed a significant difference between control and intervention groups. Recorded days of high variability may indicate an occurred exacerbation but no data collected from the program could confirm this.

The relationship between diurnal variation and asthma exacerbations has been explored in previous studies (Reddel, 1999; Aggarwal, 2000; Juniper 2012). The British Thoracic Society Guidelines stated diurnal variability can be used to both; assess whether a patient admitted to hospital for an asthma exacerbation can be discharged home safely. and as a factor to be considered when diagnosing a patient with asthma (Reddel, 1999). Diurnal variation is not the gold standard for diagnosing asthma and variation in airway size cannot simply be attributed to the presence of asthma symptoms. Diurnal variability itself is not abnormal as there are several non-asthma related factors that may cause airway narrowing or widening (Ramsale, 1986). Results from a study on well controlled asthma patient saw an increase in diurnal variability during asthma exacerbations despite an average fall in morning peak flow of $27 \%$ (Reddel, 1999). Reddel (1999) also concluded asthmatics may be susceptible to exacerbations even if their asthma is controlled for a period of time therefore diurnal variability may fail to detect significant changes in lung function.

Diurnal variation and amplitude percentage mean values may have been skewed by improper use of the peak flow meter by patients. Control patients who did not receive the 
educational intervention over the course of the program may have incorrectly used the meter as pharmacists' may not have corrected improper use. These inconsistencies could be attributed to the differences in high amplitude percentage mean over $20 \%$ in the control group verses the intervention group outlined in the results.

The results from this pilot study showed that community-based asthma interventions may have had a strong impact on diurnal variability. Further studies should consider implementing study protocol that allow for accurate recording of exacerbations of each patient on a daily basis. This may allow further investigation into the correlation between daily amplitude percentage mean and exacerbations between intervention and control groups.

\section{Limitations}

The PEFR diary entries were recorded by patients at home therefore we are unable to confirm the accuracy of recordings. Further studies can distribute electronic peak flow meters with a memory feature to verify peak flow recordings. Cote (1998) measured compliance with peak flow recordings by distributing electronic peak flow meters to patients without informing them of the 3-month memory feature of the peak flow meter. Results from this study saw poor compliance and most patients fabricating their peak flow results in their dairy at 12 months. This study also outlines the importance of using an electronic peak flow meter in studies where PEFR is an important outcome. Electronic recording on peak flow values may also be useful for homebased monitoring of asthma in order to optimize control and prevent exacerbations. The collection of data on a daily basis and delivery of this data to the pharmacist can allow one to be alerted when peak flow values are outside a specific range or exhibiting high variability.

Finkelstein (2017) was able to use machine learning algorithms to predict exacerbations before 
they occurred from patient asthma diary peak flow values that were entered into a computer at home. Home based tele-monitoring for measures other than PEFR can also provide the pharmacist access to data prior to meeting with the patient. In programs with similar protocols to this one, access to PEFR values prior to each interim visit would give the pharmacist the ability to visualize fluctuations in PEFR and advise patients accordingly. Pharmacists can also receive a clearer picture of patients' condition and be able to deliver more appropriate strategies and educational services rather than relying on the patients' word of mouth. An electronic approach to measuring can also be applied for other asthma questionnaires. This will allow for easier extraction of clinically relevant data for the pharmacist and researchers and reduce errors that exist from interpreting paper-based records.

Although data was collected on the use of all medication for the duration of the program medication dose changes were not reported here as it is beyond the scope of this paper. Changes to pulmonary function and diurnal variation may be due to medical dose changes and these dose change can also drastically affect PEFR in patients. Therefore, medication and dose changes may act as confounding variables in PEFR rates. Future studies with more patients may also see invaluable results from analyzing peak flow before and after use prescribed asthma medication.

\subsection{Program Duration}

As a pilot study, the recording of both appointment duration and program duration aided in understanding the time and resources the pharmacists devoted to interventions in comparison to standard pharmacy services for future studies.

Table 11 outlines the average duration of baseline and final visits recorded by pharmacists. We predicted both visits to take approximately 50 minutes and pharmacists were told to allot that much time for both visits. Much of the protocol the pharmacist needed to follow 
in the final visit mimicked the steps from the baseline visit therefore it was not surprising our results showed a decrease in duration of visit from baseline to final. The decrease in length of baseline and final visits between groups was also expected due to the control group pharmacists being required to complete less tasks during their patient appointments (Table 2).

Table 12 outlines the number of months between the baseline and final visit of each patient. The design of the study intended for the patients to complete all 8 visits in a 12 -month period. Pharmacists were instructed to attempt to stagger their 6 interim visits over the 12-month period with as equal intervals as possible. Depending on the schedule of the patients and the pharmacist, the time between each interim visits deferred. These differences were not reported in this document and duration between interim visits was not discussed.

One pharmacist did not follow the protocol correctly and met with their patients on more occasions than required. Three intervention patients had more than required six interim visits. The scheduling of six interim visits appointments at consistent intervals was challenging for pharmacists' and this resulted in the unpredictability of program end dates for many patients. Pharmacist scheduling difficulties were examined in exit interviews and are not reported on here.

\subsection{Recruitment Challenges}

This pilot study was part of a larger study in which data was collected for the following additional asthma measures (not discussed here): asthma control, asthma quality of life and asthma self-management. This larger study aimed to achieve similar goals as this pilot study while including analysis on the additional asthma measures. A sample size of 105 patients was the target but this was not achieved during the study and the results were not as conclusive as we predicted. Falling short of our target forced us to limit the scope of our analysis and the 
relationships between intervention and control groups became difficult to examine.

Prior to recruitment, assuming a target sample size of 105 would be achieved, statistical analysis was planned to involve running a mixed ANOVA in order to best compare differences between control and intervention groups. With a reduced sample size, the analysis was pivoted to a paired t-test in order to investigate statistical differences between baseline and final visits for both control and baseline groups.

This realignment of the statistical test was required in order to report the key findings of the program based on the sample size. It is believed a mixed ANOVA may have provided a better picture of the impact of intervention program on the asthma measures with a sufficient number of patients recruited. We believe with 19 consented patients, the reported results from paired ttest provided relevant insights of the impact of the asthma intervention program.

Due to our low sample size, we cannot generalize the conclusions from our results. A subsequent study will need a much larger sample size to be considered representative of the population.

The following outlines the recruitment challenges in Figure 2. About 2 months after the study onset in May 2016, incorrect patient information was being relayed to the research team. This issue with patient e-mails and phone numbers created difficulties for our team and reaching out to patients and consenting them took longer than expected.

In the early recruitment stages, the recruiting process had insufficient student support. One Masters research student was responsible for keeping track of multiple potential participants and ensuring communication with both pharmacists and potential participants. The rate of phone calls and e-mails to follow up with potential participants could have been increased with an extra student. The demanding workflow also affected pharmacists' ability to identify patients. Many 
pharmacists stated they were busy and overwhelmed during specific time periods such as flu season. Pharmacists also stated their lack of recruitment was due to a low number of uncontrolled asthma patients visiting week to week.

Taking the above recruitment challenges into account, the research team made modifications to our strategy. We implemented more frequent calling to increase touch points between pharmacists and research team members. Devoting more time to increasing touch points was important due to pharmacies busy schedule. This also allowed pharmacists to asks questions more often and have more direction in completing the tasks they were required to.

Additional support was added to our research team which also enabled more frequent calling and improved organization. A promotional flyer/poster was created by Ontario Pharmacists Association in which more information about the asthma study was displayed (Appendix I). This was done to engage participants when they entered the pharmacy and give them brief information about the study. A member of our research team also visited the pharmacies to discuss identification strategies such as scanning through patient lists for patients using rescue medication. The goal was to filter through pharmacy patient records for adult patients using rescue medication in order to identify potential participants. If the patient fit the study criteria, the pharmacist would reach out to the patient to let them know about the study. A teleconference with a majority of the pharmacists and owners to motivate pharmacists was also arranged. During the teleconference pharmacists were able to give our team feedback on areas that could be improved as well as discuss what strategies were or weren't not working for them. Not all participating pharmacists were able to attend due to schedule conflicts. 


\section{Conclusions}

The implementation of a pharmacist-provided comprehensive education program in a community pharmacy setting had positive impact on patients' diurnal variation, asthma-related knowledge and adherence to medication. The target sample size was not achieved and conclusions from the results cannot be generalized to the Greater Toronto Region population.

The recruitment challenges we faced improved the understanding of recruitment barriers and facilitators and assisted us in modifying our strategy. These lessons learned, to increase recruitment, may be valuable for subsequent studies adopting a similar protocol.

The modifications made to the recruitment strategy may have led to increasing the number of identified and consented patients. Creating urgency and motivating pharmacists to reach their recruitment target likely forced them to think more about the study.

Due to the length of the study, both patients and pharmacists needed to be reminded of their required tasks many times. This may have been due to the complexity of the study, and the unpredictable schedules of the participants.

\section{Recommendations}

Recruitment rates may be increased by targeted support in early phases to pharmacies with smaller patient pools (Foster, 2015). Mandating touch points between the research team and the participating pharmacist at specific times could allow for seamless communication between both parties and limit errors. Pharmacists work 24/7, therefore being able to access research support after working hours is important. This process could be more efficient by setting up some type of direct line to a research team member and this may allow pharmacists to be at ease and stay organized over the 12-month period. 
Prior assessment of pharmacies' asthma patient pool may be helpful in attaining the desired sample size. Although this was done in this study, many patients did not fall under our uncontrolled asthma criteria. It may be difficult to determine to determine the number of uncontrolled asthma patient that visit a pharmacy from just patient records.

These recruitment challenges improved our team's understanding of the barriers and facilitators of conducting an asthma management study within a community pharmacy setting. The challenges and effectiveness of the strategy medications made in this study will be very helpful in future asthma projects. 


\section{Tables}

\begin{tabular}{|c|c|c|c|}
\hline $\begin{array}{l}\text { Pharmacy } \\
\text { Number }\end{array}$ & Ownership & Number of Pharmacists & City \\
\hline 1 & Franchise & 2 & Toronto, ON \\
\hline 2 & Franchise & 2 & Toronto, ON \\
\hline 3 & Chain & 1 & Oshawa, ON \\
\hline 4 & Chain & 2 & Oshawa, ON \\
\hline 5 & Independent & 1 & Mississauga, $O N$ \\
\hline 6 & Independent & 1 & Mississauga, $O N$ \\
\hline 7 & Independent & 2 & Brampton, ON \\
\hline 8 & Independent & 1 & Barrie, ON \\
\hline 9 & Independent & 2 & Mississauga, ON \\
\hline 10 & Independent & 1 & Mississauga, ON \\
\hline 11 & Independent & 1 & Cobourg, ON \\
\hline 12 & Independent & 1 & Mississauga, ON \\
\hline
\end{tabular}

Table 2. Study Procedures and Measures

\begin{tabular}{|l|l|l|}
\hline Appointment \# & \multicolumn{1}{|c|}{ Procedures } & \multicolumn{1}{|c|}{$\begin{array}{c}\text { Questionnaires administered } \\
\text { to patient }\end{array}$} \\
\hline $\begin{array}{l}\text { Enrolment } \\
(0 \text { months })\end{array}$ & $\begin{array}{l}\text { The study pharmacist will recruit patients for participation } \\
\text { in this. If the patient meets the outlined eligibility criteria, } \\
\text { the pharmacist will: } \\
\text { Ask whether the patient is interested in participating } \\
\text { If interested collect patient contact information for } \\
\text { research team } \\
\text { The research team will contact the patient with study } \\
\text { details and formally enroll the patient by obtaining } \\
\text { informed consent (if interested) }\end{array}$ & $\begin{array}{l}\text { Demographic form to be } \\
\text { administered by research team } \\
\text { via telephone } \\
\text { (Appendix F) }\end{array}$ \\
\hline $\begin{array}{l}1: \text { Baseline } \\
(1 \text { month) }\end{array}$ & $\begin{array}{l}\text { The study pharmacist will meet with an enrolled patient } \\
\text { for an estimated 50 minutes, at a time convenient for the } \\
\text { patient and the pharmacist. During this appointment, the }\end{array}$ & $\begin{array}{l}\text { Peak Flow Diary } \\
\text { Appendix A) }\end{array}$ \\
\hline
\end{tabular}




\begin{tabular}{|c|c|c|}
\hline & $\begin{array}{l}\text { pharmacist will: } \\
\text { - Address any questions and/or concerns } \\
\text { Conduct a comprehensive medication review, } \\
\text { patient's family physician (using the Worksheet and } \\
\text { Data Collection Form) (Appendix H) } \\
\text { Provide patients with a peak flow meter, educate on its } \\
\text { proper use and requirements for daily } \\
\text { measurement/recording } \\
\text { Obtain baseline measurements using the Worksheet and } \\
\text { Data Collection Form) (Appendix H), including: } \\
\text { - Distribute and review the Peak Flow Diary } \\
\text { - Distribute, review and complete the questionnaires } \\
\quad \text { to be filled out and returned to at next appointment } \\
\text { Intervention group only: } \\
\text { Pharmacist will implement intervention(s), as needed, } \\
\text { based on each patient's situation } \\
\text { Provide patients with written materials/resources to assist } \\
\text { in ongoing management of asthma } \\
\text { Record the duration of the appointment }\end{array}$ & $\begin{array}{l}\text { Report Scale for Asthma } \\
\text { (Appendix B) } \\
\text { Asthma General Knowledge } \\
\text { Questionnaire for Adults } \\
\text { (Appendix C) }\end{array}$ \\
\hline $\begin{array}{l}2-7 \\
\text { ( } 2 \text { months }-11 \\
\text { months) }\end{array}$ & $\begin{array}{l}\text { Pharmacist will measure patient's peak flow expiratory } \\
\text { rate using the Worksheet and Data Collection Form } \\
\text { ((Appendix H) } \\
\text { Pharmacist will collect the completed diary at each visit. } \\
\text { Intervention group only: } \\
\text { - Pharmacist will implement intervention(s), as } \\
\text { needed, based on each patient's situation } \\
\text { The pharmacist will record the duration of the } \\
\text { appointment }\end{array}$ & $\begin{array}{l}\text { Peak Flow Diary } \\
\text { (Appendix A) }\end{array}$ \\
\hline
\end{tabular}




\begin{tabular}{|c|c|c|}
\hline $\begin{array}{l}\text { 8: Final } \\
\text { (12 months) }\end{array}$ & $\begin{array}{l}\text { The study pharmacist will meet with the enrolled patient } \\
\text { for the final time ( } \sim 50 \text { minutes). } \\
\text { During this appointment, the pharmacist will: } \\
\text { Refer patients to their family physician for continuing } \\
\text { treatment/management of their asthma } \\
\text { Distribute, review and complete the following questionnaires } \\
\text { to be filled out and returned to at next appointment: } \\
\text { - Asthma General Knowledge Questionnaire for } \\
\qquad \text { Adults } \\
\qquad \text { The Medication Adherence Report Scale for } \\
\text { Distribute the following questionnaire including a stamped } \\
\text { return envelope, to be filled out and returned to the OPA } \\
\text { at a later time: } \\
\text { - Patient Satisfaction questionnaire } \\
\text { Obtain final measurements (using the Worksheet and Data } \\
\text { Collection Form) (Appendix H) } \\
\text { Record the duration of the appointment } \\
\text { Control group only: } \\
\text { Provide patients with written materials/resources to assist } \\
\text { in ongoing management of asthma (intervention group } \\
\text { received it at study baseline) }\end{array}$ & $\begin{array}{l}\text { Peak Flow Diary } \\
\text { (Appendix A) } \\
\text { The Medication Adherence } \\
\text { Report Scale for Asthma } \\
\text { (Appendix B) } \\
\text { Asthma General Knowledge } \\
\text { Questionnaire for Adults } \\
\text { (Appendix C) }\end{array}$ \\
\hline
\end{tabular}


Table 3. Patient Questionnaires

Questionnaire Title

Measure

Range of Scores

(poor to excellent)

Validated

Medication Adherence

Report Scale for Asthma

patients' medical adherence to inhaled corticosteroids

$1-5$

Yes

Asthma General Knowledge Questionnaire for Adults

patients' knowledge of asthma

$0-100$

Yes

Table 4. Pharmacy Reimbursement

\begin{tabular}{|c|c|c|c|c|}
\hline Category & Estimated time & Compensation & $\begin{array}{l}\text { Intervention } \\
\text { group }\end{array}$ & $\begin{array}{l}\text { Control } \\
\text { group }\end{array}$ \\
\hline $\begin{array}{l}\text { Patient baseline assessment } \\
\text { appointment }\end{array}$ & 30 mins & $\$ 80$ & $\sqrt{ }$ & $\sqrt{ }$ \\
\hline Medication review and plan & 25 mins & $\begin{array}{c}\$ 60(\text { OPDP })+\$ 15 \\
(\text { Top-Up by Study) } \\
=\$ 75\end{array}$ & $\sqrt{ }$ & \\
\hline $\begin{array}{l}\text { Medication review } \\
\text { follow- up }\end{array}$ & $15 \mathrm{~min}$ & $\$ 25$ (OPDP) & $\sqrt{ }$ & \\
\hline $\begin{array}{l}\text { Smoking cessation } \\
\text { counseling (initial assessment) }\end{array}$ & $30 \mathrm{~min}$ & $\$ 40$ & $\sqrt{ }$ & \\
\hline $\begin{array}{l}\text { Smoking cessation counseling } \\
\text { (follow-up; up to } 8 \text { ) }\end{array}$ & $3-10 \mathrm{~min}$ & $\begin{array}{l}\text { For patient under } 65 \\
\text { years of age Primary } \\
\text { follow-up } \\
\text { (\$15) Secondary } \\
\text { follow-up }(\$ 10)\end{array}$ & $\sqrt{ }$ & \\
\hline $\begin{array}{l}\text { Patient final assessment } \\
\text { appointment }\end{array}$ & $25 \mathrm{mins}$ & $\$ 60$ & $\sqrt{ }$ & $\sqrt{ }$ \\
\hline
\end{tabular}


Table 5. Amplitude Mean \% Calculation

2016-10-30

$1^{\text {st }}$ Recording

Morning

Evening

$2^{\text {nd }}$ Recording

625

600

$3^{\text {rd }}$ Recording

650

575

Maximum of 3 Recordings

600

600

$\mathrm{A} \% \mathrm{M}$ Variability

650

600

$8.00 \%$

Amplitude percent mean calculation:

$(650-600) \div(650+600) \div 2))=8.00 \%$

\begin{tabular}{lccc}
\hline Table 6. Pharmacist Demographic Results & & \\
\hline$n=13$ & Intervention & Control & Both Groups \\
\hline Females & 7 & 3 & 10 \\
Males & 2 & 1 & 3 \\
Full Time & 8 & 1 & 9 \\
Part Time & 1 & 2 & 3 \\
Pharmacy Owner & 4 & 0 & 4 \\
Age (avg) & 40 & 49 & 44 \\
Prescriptions per day (avg) & 159 & 173 & 166 \\
Years working (avg) & 15.6 & 23 & 19 \\
\hline
\end{tabular}




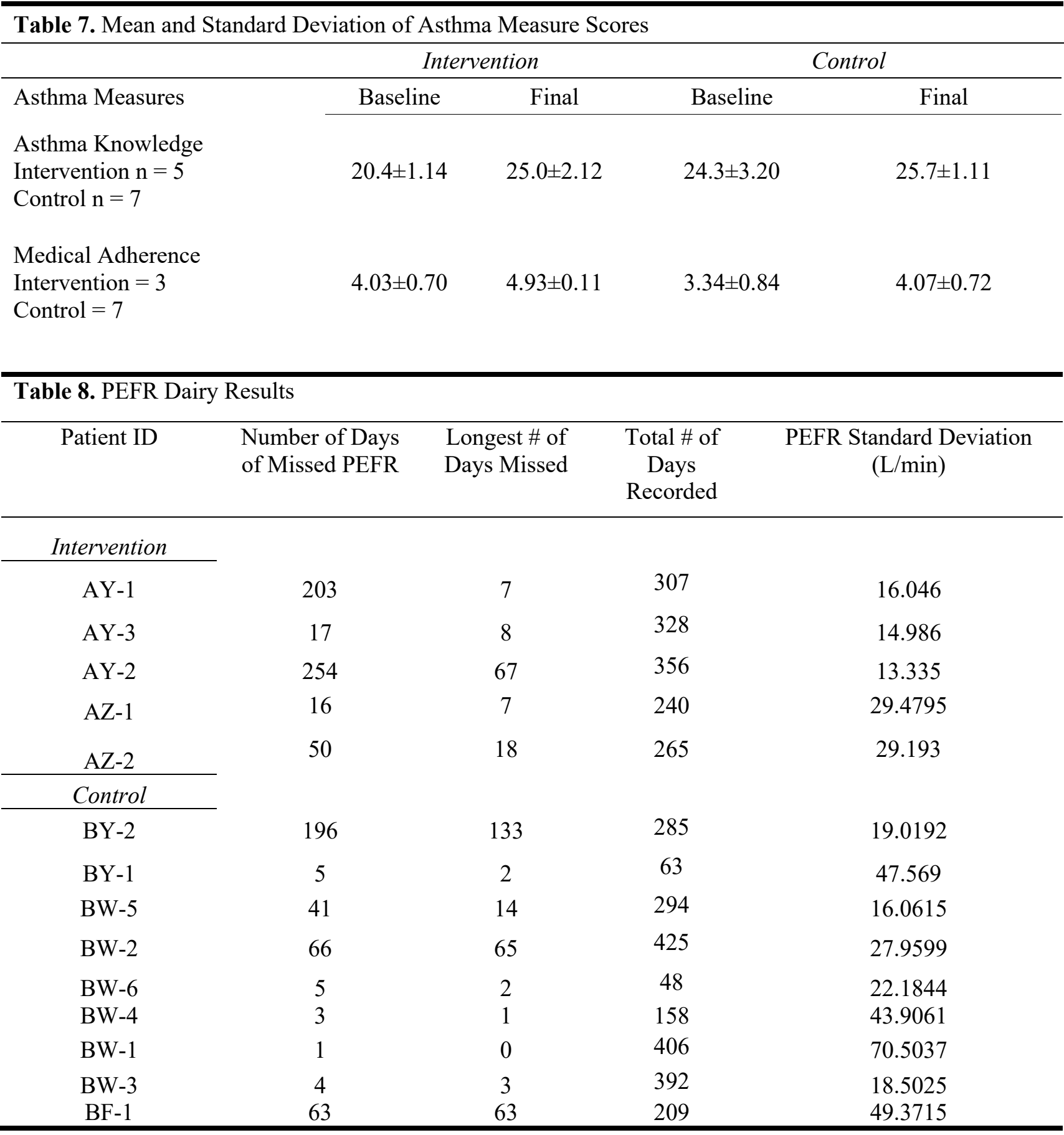




\begin{tabular}{|c|c|c|c|c|}
\hline & \multicolumn{2}{|c|}{ Mean } & \multicolumn{2}{|c|}{ Median } \\
\hline & Intervention & Control & Intervention & Control \\
\hline $\begin{array}{c}\text { Number of Days of Peak } \\
\text { Flow Recorded }\end{array}$ & $299 \pm 41$ & $253 \pm 135$ & 307 & 285 \\
\hline $\begin{array}{c}\text { Longest Number of } \\
\text { Consecutive Days Missed }\end{array}$ & $21.4 \pm 23$ & $31.4 \pm 43$ & 8 & 3 \\
\hline $\begin{array}{c}\text { Total Number of Days } \\
\text { Missed }\end{array}$ & $108 \pm 100$ & $42.7 \pm 59$ & 50 & 5 \\
\hline Percentage of Days Missed & $33.6 \% \pm 29 \%$ & $16.7 \% \pm 20 \%$ & $18.9 \%$ & $10.4 \%$ \\
\hline
\end{tabular}

Table 10. High Diurnal Variation of PEFR

\begin{tabular}{ccc}
\hline Group & $\begin{array}{c}\text { Number of Days of Amplitude Mean } \\
>20 \%\end{array}$ & $\begin{array}{c}\text { \% of Total Peak Flow Days of } \\
\text { Amplitude Mean }>20 \%\end{array}$ \\
\hline Intervention & 0 & $0 \%$ \\
AY-1 & 0 & $0 \%$ \\
AY-3 & 0 & $0 \%$ \\
AY-2 & 0 & $0 \%$ \\
AZ-1 & 2 & $0.7 \%$ \\
AZ-2 & 0 & $0 \%$ \\
AF-2 & & \\
Control & 18 & $6.6 \%$ \\
BY-2 & 5 & $7.9 \%$ \\
BY-1 & 1 & $0.33 \%$ \\
BW-5 & 0 & $0 \%$ \\
BW-2 & 7 & $6.6 \%$ \\
BW-6 & 14 & $8.4 \%$ \\
BW-4 & 46 & $11 \%$ \\
BW-1 & 5 & $1.3 \%$ \\
BW-3 & 7 & $3.4 \%$ \\
BF-1 & 5
\end{tabular}


Table 11. Mean Duration of Visit

\begin{tabular}{ccccc}
\hline & $\begin{array}{c}\text { Intervention } \\
\mathrm{n}=5\end{array}$ & \multicolumn{2}{c}{$\begin{array}{c}\text { Control } \\
\mathrm{n}=9\end{array}$} \\
\hline Baseline & & Final & Baseline & Final \\
54.00 & 33.7 & 42.2 & 17.85 \\
\hline
\end{tabular}

Note: All units are in minutes. 3 patients are missing from Table due to unconfirmed start and end dates.

Table 12. Study Completion Duration of each Patient

\begin{tabular}{cc}
\hline Group & Time Between Baseline and Final Visits (months) \\
\hline Intervention & \\
\hline AY-1 & 9.5 \\
AY-2 & 12.4 \\
AY-3 & 11.0 \\
AZ-1 & 9.6 \\
AZ-2 & 20.8 \\
Control & \\
BF-1 & 10.1 \\
BW-1 & 13.5 \\
BW-2 & 13.9 \\
BW-3 & 13.1 \\
BW-4 & 7.5 \\
BW-5 & 9.8 \\
BW-6 & 7.5 \\
BY-2 & 9.8 \\
\hline
\end{tabular}




\section{Figures}

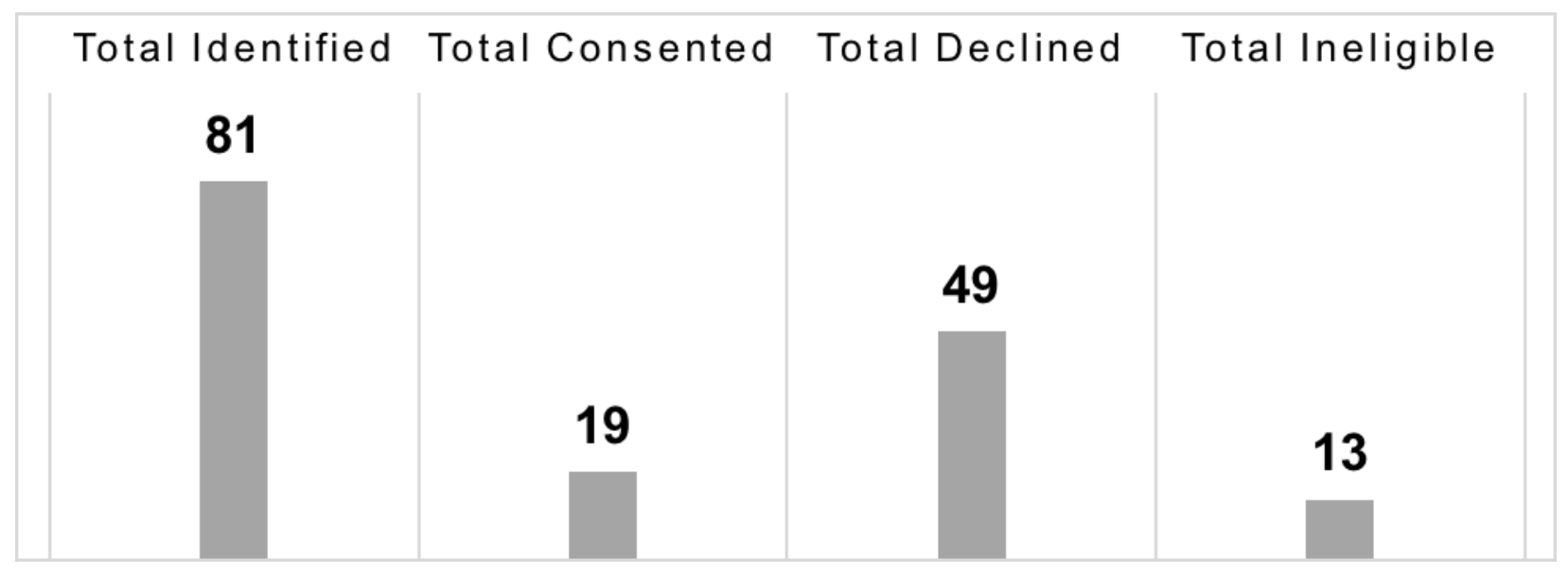

Figure 1. Total Consented Identified and Declined as of December 2017.
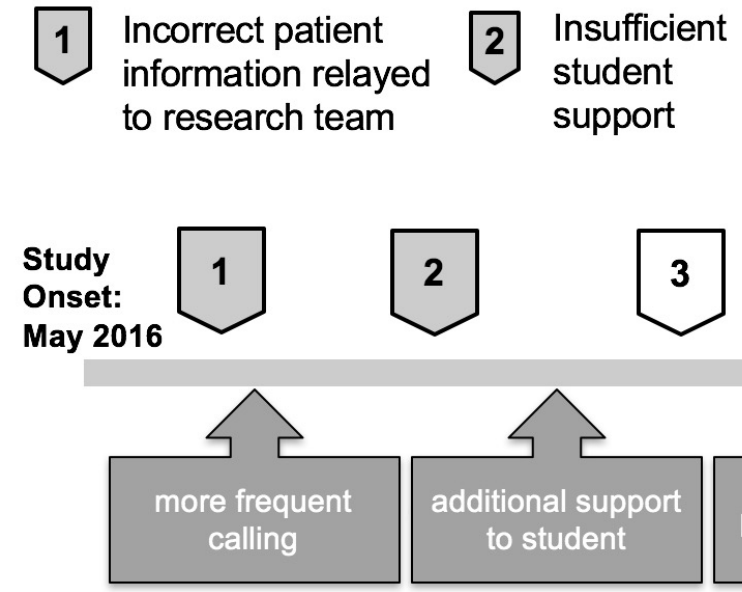 3 Demanding affected identifying patients
4 Low number of uncontrolled asthma patients visiting pharmacy

Figure 2. Recruitment Challenges and Modifications

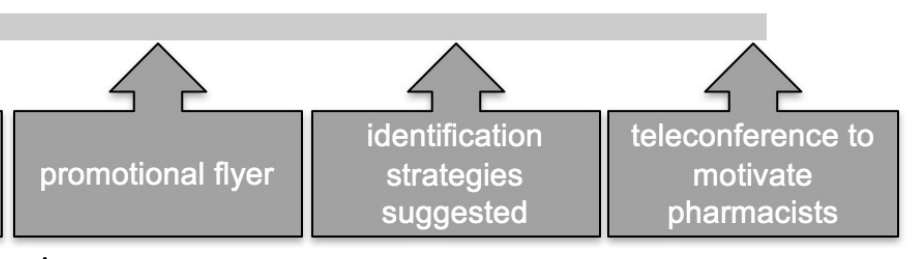
2017 


\section{Appendices}

\section{Appendix A. Peak Flow Diary}

Patient ID:

Date:

Please record your peak flow measurements 6 times daily and report them on this form. Three measurements will be performed in the morning, and 3 measurements will be performed in the evening.

\begin{tabular}{|c|c|c|c|c|c|c|c|}
\hline Dates & Sunday & Monday & Tuesday & Wednesday & Thursday & Friday & Saturday \\
\hline & $\begin{array}{l}\text { Morning: } \\
\text { (1) }\end{array}$ & $\begin{array}{l}\text { Morning: } \\
\text { (1) }\end{array}$ & $\begin{array}{l}\text { Morning: } \\
\text { (1) }\end{array}$ & $\begin{array}{l}\text { Morning: } \\
\text { (1) }\end{array}$ & $\begin{array}{l}\text { Morning: } \\
\text { (1) }\end{array}$ & $\begin{array}{l}\text { Morning: } \\
\text { (1) }\end{array}$ & $\begin{array}{l}\text { Morning: } \\
\text { (1) }\end{array}$ \\
\hline & (2) & (2) & (2) & $(2)$ & (2) & (2) & $(2)$ \\
\hline & (3) & (3) & (3) & (3) & (3) & (3) & (3) \\
\hline & $\begin{array}{l}\text { Evening: } \\
\text { (1) }\end{array}$ & $\begin{array}{l}\text { Evening: } \\
\text { (1) }\end{array}$ & $\begin{array}{l}\text { Evening: } \\
\text { (1) }\end{array}$ & $\begin{array}{l}\text { Evening: } \\
\text { (1) }\end{array}$ & $\begin{array}{l}\text { Evening: } \\
\text { (1) }\end{array}$ & $\begin{array}{l}\text { Evening: } \\
\text { (1) }\end{array}$ & $\begin{array}{l}\text { Evening: } \\
\text { (1) }\end{array}$ \\
\hline & (2) & (2) & (2) & $(2)$ & (2) & (2) & $(2)$ \\
\hline & (3) & (3) & (3) & (3) & (3) & (3) & (3) \\
\hline
\end{tabular}




\section{Appendix B. Medication Adherence Report Scale for Asthma (MARS-A)}

\section{Medication Adherence Report Scale for Asthma (MARS-A)}

\section{Patient ID}

How often do you do the following with respect to your asthma controller medication (inhaled steroid):

The Medication Adherence Report Scale for Asthma (MARS-A)

How often do you do the following?

\begin{tabular}{|c|c|c|c|c|c|}
\hline Question & $\begin{array}{c}\text { Always } \\
\text { (1) }\end{array}$ & $\begin{array}{c}\text { Often } \\
\text { (2) }\end{array}$ & $\begin{array}{c}\text { Sometimes } \\
\text { (3) }\end{array}$ & $\begin{array}{c}\text { Rarely } \\
\text { (4) }\end{array}$ & $\begin{array}{c}\text { Never } \\
\text { (5) }\end{array}$ \\
\hline I only use my [name of medicine] when I ne & & & & & \\
\hline I only use it when I feel breathless & & & & & \\
\hline I decide to miss out a dose & & & & & \\
\hline I try to avoid using it & & & & & \\
\hline I forget to take it & & & & & \\
\hline I alter the dose & & & & & \\
\hline I stop taking it for a while & & & & & \\
\hline $\begin{array}{l}\text { I use it as a reserve, if my other treatment } \\
\text { doesn't work }\end{array}$ & & & & & \\
\hline $\begin{array}{l}\text { I use it before doing something which might } \\
\text { make me breathless }\end{array}$ & & & & & \\
\hline I take it less than instructed & & & & & \\
\hline
\end{tabular}




\title{
Appendix C. Asthma General Knowledge Questionnaire for Adults
}

\author{
Asthma General Knowledge Questionnaire for Adults (AGKQA)
}

\section{Patient ID}

Here are some questions about asthma in general. Circle T, if you think the statement is true; F, if you think that the statement is false; NS, if you are not sure or do not know whether the statement is true or false.

1. Left untreated, asthma will eventually go away. [T or F]

2. Asthma is a nervous or psychological illness. [T or F]

3. Asthma is a breathing problem that may be triggered by strong emotions. [T or F]

4. Regular exercise such as swimming can cure asthma. [T or F]

5. Exercise can help keep you fit and well and better able to cope with asthma. [T or F]

6. Exercising until you become breathless can damage the heart and/or lungs. [T or F]

7. You should not exercise if exercise brings on even the occasional asthma attack. [T or F]

8. Some medications taken 10 minutes before exercising, can stop you from getting asthma when you exercise. [T or F]

9. Some medications can be used during exercise if you get asthma. [T or F]

10. Only a doctor can call an ambulance for you. [T or F]

11. Medication returns the airtubes to normal and no permanent damage usually occurs. [T or F]

12. You can become addicted to asthma medications if you use them all the time. [T or F]

13. Asthma medications do not work as well if you use them all the time. [T or F]

14. Although it can not be cured, asthma can usually be controlled by taking the correct medication. [T or F]

15. Side-effects are less likely with inhaled medication than with tablets because inhaled medication is not absorbed into the body. [T or F]

16. Syrups and tablets work about as quickly as inhaled medications. [T or F]

17. If you get a cold or flu, you should increase your asthma medications. [T or F]

18. A doctor is best able to measure how bad asthma is by listening to the chest with a stethoscope. [T or F]

19. Measing the amount of air in the lungs with a peak flow meter or spirometer is the most accurate way of measuring how bad asthma is. [T or F]

20. Most asthma deaths could have been prevented. [T or F]

21. If a person has died from an asthma attack, it usually means that the attach must have begon so quickly that there was no time to start treatment. [T or F]

22. You may have fewer asthma attacks if you can identify and avoid things that trigger them. [T or F]

23. When asthma is well controlled by medication it is not triggered so easily. [T or F]

During an asthma attack: ....

24. ......the muscles around the airtubes tighten and the tubes become narrow. [T or F]

25. ......more mucus is produced in the airtubes[ $\mathrm{T}$ or $\mathrm{F}]$ 
26. ......the lining of the airtubes becomes swollen. [T or F]

27. ......the changes in the airtubes make it difficult to get the air out of the lungs[T or F]

28. .....the airtubes collapse $[\mathrm{T}$ or $\mathrm{F}]$

29. ....the chances in the airtubes make it difficult to get the air into the lungs. [T or F]

When you know that you are going to be exposed to something that triggers your asthma.....

$30 \quad$....you should take medication just before exposure. $[\mathrm{T}$ or $\mathrm{F}]$

$31 \quad$......you should wait until you develop symptoms before taking medication. [T or F] 


\section{Appendix D. Study Services Agreement}

THIS AGREEMENT is made in duplicate on X

\section{BETWEEN:}

\author{
Pharmacy Owner \\ (hereinafter called "Owner") \\ - and - \\ Study Pharmacist \\ (hereinafter called "Study Pharmacist")
}

- and -

Ontario Pharmacists' Association

(hereinafter called "OPA")

Context and Purpose

The OPA is conducting an impact study which requires the involvement and agreement of pharmacies and

Pharmacists. For purposes of this agreement, the use of "Study" shall refer to all aspects of the "A Pilot Test and

Evaluation of a Community Pharmacist Managed Asthma Consultation Service". The "Study Pharmacist" shall refer to all pharmacists enrolled in the study.

Subject to the terms and conditions in this Agreement, the parties agree as follows:

\subsection{SERVICES}

The services to be provided by the Study Pharmacists through this Agreement are attached as Appendix A.

The Study Pharmacist is required to attend a mandatory orientation/training session, to be held at the Ontario Pharmacists' Association office at 375 University Avenue, Suite 800, Toronto, ON M5G 2J5.

The services to be provided through this Agreement by the Owner are as per below: 
- To provide the Study Location with the logistical, technological and other supports necessary for their effective participation in this study, in cooperation with the OPA.

\subsection{DURATION}

This Agreement begins on the day it is executed and terminates according to the Study timelines, as prepared and identified by the OPA. Based on the progress of the Study, the deadline may be extended as the OPA sees fit. The Study Pharmacist agrees that all patient interactions as related to this study between Study Pharmacists and Study patients will be held at the Study Pharmacist's primary pharmacy of practice (Study Location).

\subsection{EARLY TERMINATION}

3.1 Notwithstanding Paragraph 2.0, OPA reserves the right to terminate this Agreement on 14 days written notice to the Study Pharmacist.

3.2 If OPA terminates this Agreement at any point, OPA shall only be responsible for the outstanding stipend of such amount in respect of expenses accumulated for Study activities performed up to and including end of business on the date of termination,

\subsection{REMUNERATION}

4.1 The OPA shall provide the Study Pharmacist with an Honorarium upon completion of the Study for the following items of compensation:

- Study Pharmacist in the control group: attendance of a live training session - $\$ 180$

- Study Pharmacist in the intervention group: Attendance of a live training session - $\$ 360$

- $\quad$ Patient Enrolment Incentive (the Study Pharmacist must enroll 8 patients) - \$125

4.2 The Owner and the Study Pharmacist shall be responsible for the payment of all applicable federal, provincial and municipal taxes, permits, fees, insurance deductions, pensions, or any other claim or deduction requested by a government in respect of compensation under this Agreement.

4.3 OPA shall reimburse the Owner for all costs outlined in the Study Pharmacist Services Agreement

\subsection{REPORTING}


For any questions as related to the Study or this Service Agreement, the Study Pharmacist will contact Mr. Lee Verweel at the OPA (see Appendix A), on the status of services as deemed appropriate by both parties and in a timely fashion.

\subsection{INDEMNIFICATION}

The Owner and the Study Pharmacist agrees to indemnify and save harmless OPA, its officers, employees and agents for liability resulting from any injury or damage (including death), property loss, or damage sustained by the Owner or Study Pharmacist .

\subsection{PROPERTY AND POSSESSION}

7.1 OPA may take possession of and use any completed or partially completed portions of the work undertaken as a volunteer in its program in performance of Study Pharmacist services, including de-identified Study Patient data collected as part of the Study. OPA or persons authorized by OPA may at all reasonable times inspect or otherwise review the progress of said work.

7.2 All Study Patient data collected and associated documents prepared by the Study Pharmacist in the course of the performance of the services shall be the property of the OPA. Should the OPA request copies of the hard-copy format of the Study Patient data collected as part of the Study, the Study Pharmacist is obligated to provide a copy within a reasonable length of time.

7.3 Upon receipt of a written request from OPA, and in any event after the services under this Agreement have been completed or at early termination of the Agreement, the Study Pharmacist shall promptly deliver to the OPA all materials which are the property of OPA and in the possession or under the control of the Study Pharmacist, Owner or the Study Location.

\subsection{CONFIDENTIALITY}

8.1 The Study Pharmacist shall, both during and following the Term of this Agreement, treat as confidential and safeguard any information or document concerning the affairs of OPA of which the Study Pharmacist, the Owner or any of their organizations acquire knowledge or that comes into its or their possession by reason of its or their business with OPA under this Agreement and shall not disclose either directly or indirectly any such information or document to any person, firm or corporation without first obtaining the written permission of OPA.

8.2 The Study Pharmacist shall, both during and following the Term of this Agreement, treat as confidential and safeguard any information or document concerning StudyPatients.

8.3 The Study Pharmacist shall not disclose any Study Patient data information as related to the Study to any person or entity outside the Study. 
8.4 Paragraph 8.0 survives the completion or early termination of this Agreement.

9.0 CONFLICT OF INTEREST

The Study Pharmacist warrants that they shall not during the term of this Agreement provide any services to any person, corporation, body, group or organization where the provision of such services, actually or potentially, creates a conflict of interest with the provision of the services pursuant to this Agreement, without the Study Pharmacist first disclosing to OPA the actual or potential conflict of interest and obtaining the express prior written consent of OPA to perform such work as a volunteer in our program without limitation.

The Owner warrants that it, its partners, directors, officers, employees, agents, contractors, subcontractors and volunteers shall not during the term of this Agreement provide any services to any person, corporation, body, group or organization where the provision of such services, actually or potentially, creates a conflict of interest with the provision of the Services pursuant to this Agreement, without Owner first disclosing to OPA the actual or potential conflict of interest and obtaining the express prior written consent of OPA to perform such work as a volunteer in our program without limitation.

\title{
10.0 INSURANCE
}

The Owner and the Study Pharmacist will, on request, provide OPA with certificates or other evidence of Professional Liability Insurance, for coverages and amounts satisfactory to OPA for personal injury or property damage.

\subsection{AMENDMENT}

No change to or modification of this Agreement shall be valid unless it is in writing and signed by OPA, the Study Pharmacist and the Owner.

\subsection{REPRESENTATIVES AND NOTICES}

12.1 For the purpose of this Agreement, the Study Pharmacist shall be contacted as follows:

Name :

Address :

Telephone:

12.2 For the purpose of this Agreement, OPA shall be contacted as follows:

\author{
Allan Malek, SVP Professional Affairs \\ Ontario Pharmacists' Association
}

375 University Ave Suite 800

Toronto ON M5G 2J5 
Tel: 416-441-0788 ext. 4239

For the purpose of this Agreement, the Owner shall be contacted as follows:

Name of Pharmacy:

Name of Owner:

Address:

Telephone:

\subsection{ASSIGNMENT}

The Study Pharmacist shall not assign this Agreement or any part thereof, without the prior written approval of OPA which approval may be unreasonably withheld.

IN WITNESS WHEREOF, the Parties hereto have executed this Agreement as of the date first written above.

\section{SIGNED, SEALED AND DELIVERED}

In the presence of:

Dennis A. Darby, ICD.D,

Chief Executive Officer

For and on behalf of:

ONTARIO PHARMACISTS' ASSOCIATION

Study Pharmacist Name

(Please Print)

Study Pharmacist Signature 
Pharmacy (Study Location) Name

Owner Name

(Please Print)

Owner Signature

For and on behalf of:

"Pharmacy Owner" 


\section{Appendix E. Pharmacist Demographic Questionnaire}

\section{Pharmacist Demographic Questionnaire}

To be completed by the interviewer with the participant prior to scheduled interview.

1. What is your current age in years?:

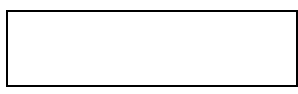

2. What is your gender

Which of the following best describes you? (check all that apply)
a. $\square$ Male
b. $\square$ Female
c. (for example, transgender)

3. Where is your pharmacy located?

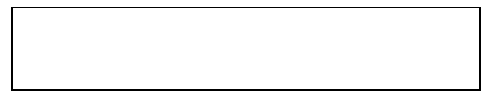

4. What services do you provide?

$\square$ MedsCheck

$\square$ Smoking Cessation

$\square$ Other:

5. Are you currently working in collaboration with other healthcare providers?

$\square$ Yes
$\square$ No

If yes, describe:

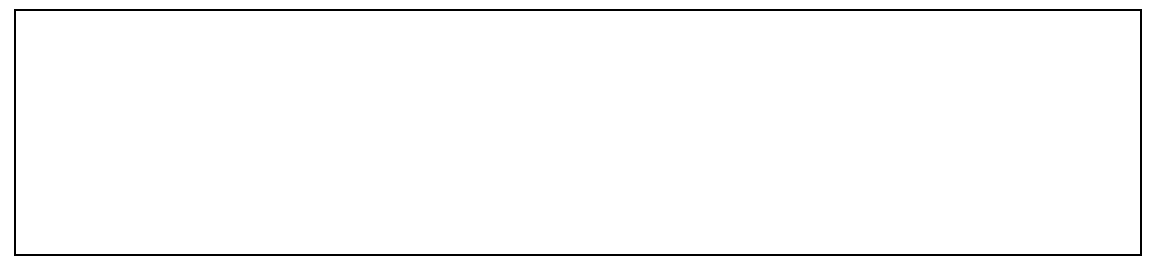

6. What is your employment status?

$\square$ Full-time staff pharmacist

$\square$ Part-time staff pharmacist

$\square$ Pharmacy manager

Pharmacy owner 
$\square$ Franchisee

Freelance/relief pharmacist

Other

7. How long have you been a pharmacist?

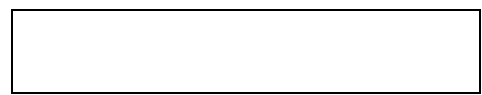

8. Do you have any additional post-graduate training and/or certification (e.g. geriatric pharmacy, certified diabetes educator, certified respiratory educator, etc.).

$\square$ Yes

$\square$ No

If yes, describe:

9. Approximately how many prescriptions does the pharmacy dispense in a typical day?

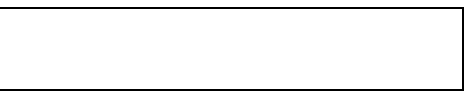

10. How many pharmacists (including part-time, full-time, and manager/owner) are currently employed in the pharmacy?

11.

oes the pharmacy have a private counseling room?

$\square$ Yes
$\square$ No

$* * *$ Thank you for completing this survey*** 


\section{Appendix F. Patient Demographic Questionnaire}

\section{Patient Demographic Questionnaire}

\section{Patient ID}

1. What is your current age:

years

2. What is your gender

Which of the following best describes you? (check all that apply)
a. $\square$ Male
b. $\square$ Female
c. (for example, transgender)

3. What is the highest level of education you have completed
a. Elementary school
b. High school
c. College/University
d. Graduate-level (e.g. Masters, PhD)

4. What is your gross household income
a. $<\$ 25,000$
b. $\$ 25,000$ to $\$ 45,000$
c. $\$ 45,001$ to $\$ 65,000$
d. $\$ 65,001$ to $\$ 85,000$
e. $\$ 85,001+$

5. What is your employment status?
a. Employed Full Time
b. Employed Part Time
c. Retired
d. Unemployed
e. Student

\section{Appendix G. Patient Consent Form}




\section{Ryerson University \\ Letter of Information and Consent Agreement for Patients}

TITLE: Pilot Test and Evaluation of a Community Pharmacist Managed Asthma Consultation Service

INVESTIGATORS: This research study is being conducted by Mr. John Odame under the supervision of Drs. Pria Nippak and Zahava Rosenberg-Yunger at Ryerson University.

OVERVIEW: You are being asked to participate in a research study as part of Mr. John Odame's Master's thesis project being conducted in partial fulfilment of his Master's degree at Ryerson University. Please read this document which outlines details about the study and the consent process. Before you consent to participate, please ask any questions to be sure you understand what your participation will involve.

This study is funded by AstraZeneca and GlaxoSmithKline and being conducted in collaboration with the Ontario Pharmacists Association (OPA). OPA will provide logistical and administrative support to Mr. Odame..

\section{PURPOSE OF THE STUDY:}

Given the scientific evidence of pharmacists' role in asthma management there is a strong rationale for introducing a pharmacists' intervention for asthma management (this includes review of medication, patient support and management of disease) for Ontarians suffering from asthma. Before starting such a program there is a need for pilot testing to make sure that the program improves patient care. The goal of this study is to look at the effect of a community pharmacist on your asthma management.

This study will consist of a prospective, randomized controlled trial conducted in the community pharmacy setting. Patients will be randomly assigned to either the control or intervention group. All patients will have an equal probability of being assigned to either group and this will be determined at the pharmacy level (that is pharmacies will be notified whether they are part of the control or intervention group). Procedures will be controlled to ensure that all participants in each group are treated the same except for intervention group participants receiving interventions from the pharmacists. Therefore, all parties (including yourself and your pharmacist) will be aware of your treatment group. A total of 105 patients across 12 pharmacies within the Greater Toronto Region will be recruited for this study.

\section{ELIGIBILITY CRITERIA}

In order to be eligible to participate in this study you must be at least 18 years of age and have a diagnosis of asthma from a physician or nurse practitioner. You must also be taking inhaled corticosteroids for which the dose and/or medication has remained unchanged for at least 2 months. Additionally, you must have uncontrolled asthma which has been defined in this study as follows:

In the past 4 weeks you have

- Used your rescue medications 4 or more times in a given week

And/or

- Woken up in the night from your asthma in a given week

Finally, you must intend to refill all asthma prescriptions at the study pharmacy.

You will be ineligible to participate in this study:

- If you are pregnant

- If you are terminally ill or have a poor prognosis (life expectancy less than 3 years)

- If you have a history of alcoholism or drug abuse

- If you have a chronic obstructive pulmonary disorder (emphysema; chronic bronchitis)

- If you have an acute respiratory infection

- If you have a pulmonary fibrosis 
- If you have had cancer (in the past 5 years preceding enrolment)

- If you have had an organ transplantation

- If you have dementia

- If you have a cognitive impairment or other psychiatric disorder

- If you have any other health issue that may hinder performance on pulmonary function test.

- If you are enrolled in an Employee Assistance Program for disease management within 6 months preceding the study enrolment date OR planning to enroll in the next 12 months

- If you are enrolled in another asthma management/clinical study OR planning to enroll in a similar study in the next 12 months

- If you have had a MedsCheck or MedsCheck Follow-Up done within the 3-month period preceding the anticipated date of the first study appointment

- If you do not wish your physician to be notified of your participation in this study

YOU WILL BE ASKED TO DO THE FOLLOWING: If you decide to participate in this study, you will be asked to do the following (see summary table below):

1. Recruitment and Consent: If you are interested in participating in this study, you will be screened for eligibility. The pharmacist who recruits you for the study will:

- Contact you and provide you with the details of the study; and

- If you are interested in participating in our study, the pharmacist will ask you for your contact information (i.e., phone number and/or email)

Our research team will then contact you either through phone or email with further study details and review the consent process with you. Patients who express interest in participating will be given one week to review the consent and study information. After one week we will contact you again.

If you consent we will ask you to complete a demographic form with one of our researchers over the phone. This will take approximately 10 minutes. We will also contact your pharmacist to advise them of your participation in this study.

During your interaction with the pharmacist throughout the study the pharmacist will enter your data collected as part of this research study into pre-developed paper-based and or electronic forms. The pharmacist will also retain the paper copies of the questionnaires completed by you throughout the study.

2. Baseline Assessment (approximately 50 minutes): The study pharmacist will meet with you for an estimated 50 minutes, at a time convenient for you and your pharmacist. During the initial visit your pharmacists will:

- Address any questions and/or concerns you have about the study

- Conduct a comprehensive medication review, develop a medication plan and fax it to your family physician

- Provide you with a peak flow meter, educate you on its proper use and requirements for daily measurement/recording

- Obtain baseline measurements, including:

$\circ \quad$ Patient height and weight

- Self-reported health system usage in the past 6 months

- Number of prescription medications currently taken

- Number of current co-existing diagnosed health conditions

- Pulmonary function

- Adherence to inhaled corticosteroid medication therapy

- Smoking status/frequency

- Asthma-related quality of life

- Symptom severity

- Asthma control

- A 10 dollar gift card will be given to you after completion of the baseline assessment

\section{Measure peak flow (approximately 5 minutes):}


You will use the peak flow meter (given to you at the initial appointment) to measure your daily peak flow. You will record this on the Peak Flow Diary and give the completed form to your pharmacist at each visit.

\section{Follow up Assessments (approximately 5 minutes):}

At appointments 2-7, you will be asked to:

- Measure your peak flow. Only the intervention group will receive components of the intervention(s) based on your situation.

- A $10 \$$ gift card will be given to you after the $3^{\text {rd }}$ and $6^{\text {th }}$ appointments

5. Final Assessment (approximately 50 minutes: At the final appointment of this research study, your pharmacist will meet with you and provide the following services:

- Refer you to your family physician and provide continuing treatment/management of your asthma

- Distribute a service satisfaction questionnaire to you, which will include a stamped return envelope to be filled out and return to the Ontario Pharmacist association at a later time.

- Once OPA receives your completed questionnaire they will mail you a \$20 gift card

- Obtain final measurements on:

- Self-reported health system usage in the past 6 month

- Number of prescription medications currently taken

○ Pulmonary function

- Adherence to inhaled corticosteroid medication therapy

$\circ$ Smoking status/frequency

- Asthma related quality of life

○ Symptom severity

- Asthma control

- Record the duration of the appointment

If you are part of the control group you will be provided with written materials/resources to assist in ongoing management of asthma but you will not receive any other interventions for asthma.

\section{POTENTIAL BENEFITS:}

There is no guarantee that this study will provide any benefits to you. You will be given a peak flow meter at the onset of the study which you can keep beyond the completion of the study. Also, results from this study will help inform pharmacy practice in asthma management in the future.

\section{THE POTENTIAL RISKS TO YOU AS A PARTICIPANT:}

There are minimal risks to you being involved in this study. This study may cause uncomfortable feelings as you may recall how you have managed your asthma in the past and identify risk factors that you were not aware of prior to this study, including smoking or other lifestyle habits that negatively affect your asthma.

\section{CONFIDENTIALITY:}

All the information we collect about you will be kept confidential. All paper forms will be kept by your pharmacist in a secure location. Our team will collect the hard copies of forms at the end of the study and keep them in a locked cabinet. Data will be kept for 10 years and may be used for data analysis for a project unrelated to this one.

Paper based data collection forms filled out by your pharmacist throughout the study will be disposed of 
in a manner that leaves no possibility for reconstruction of information. Electronic based data collection forms completed by your pharmacist throughout the study will be disposed of permanently. We will not make anything public that might identify you, unless legally required to do so. Your pharmacist will be aware of who participates in this study and both you and the pharmacist will know which group your pharmacy is assigned to. Although, data will remain confidential as data will be de-identified and stored in a password protected computer. Further, any data that will be taken away from our site will be transferred on to a password protected storage device.

\section{INCENTIVES FOR PARTICIPATION:}

Your pharmacist will provide you with a 10 dollar gift card upon your completion of the first appointment third and sixth appointments. You received a 20 dollar gift card upon your completion the study.

\section{COSTS TO PARTICIPATION:}

There will be no cost to participate in this study.

\section{VOLUNTARY PARTICIPATION AND WITHDRAWAL:}

Your participation in this study is completely voluntary. You may choose whether to participate in this study or not. If any question makes you uncomfortable, you can skip that question. You may stop participating at any time. If you choose to stop participating, you may also choose to have your data withdrawn from the study. If you withdraw from the study and wish that your data is not used for research purposes, then we will remove your data. If you have missing data based on choosing to not answer particular questions, we will include the data for the answered questions only. If your pharmacist withdraws from the study we will approach the second pharmacist and ask that they take you on as their patient and submit their data. Should both study pharmacists decide to withdraw from the study then you will receive educational pamphlets.

\section{ALTERNATIVES TO PARTICIPATION:}

Should you decide not to participate in this study it will not affect your relationship with the Ontario Pharmacists Association or Ryerson University. If you choose not to participate in the study, standard pharmaceutical care will still be offered by the pharmacy.

This study has been reviewed by the Ryerson University Research Ethics Board. If you have questions regarding your rights as a participant in this study please contact:

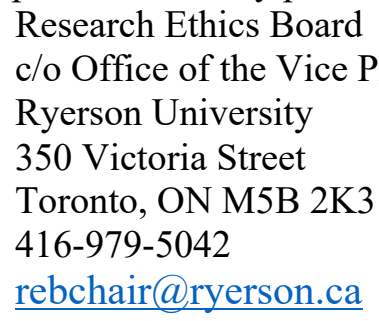

This study is registered at ClinicalTrials.gov (https://clinicaltrials.gov) with the identifier: NCT02768623

$\underline{\text { Pilot Test and Evaluation of a Community Pharmacist Managed Asthma Consultation Service }}$ 


\section{CONFIRMATION OF AGREEMENT:}

Your signature below indicates that you have read the information in this agreement and have had a chance to ask any questions you have about the study. Your signature also indicates that you agree to participate in the study and have been told that you can change your mind and withdraw your consent to participate at any time. You will be given a copy of this agreement.

By signing this consent agreement you are not giving up any of your legal rights.

Name of Pharmacist (please print)

Signature of Pharmacist

Date

Please let us know where to mail your final gift card by providing us with your mailing address below:

Street name:

City:

Province:

Postal Code: 


\section{Appendix H. Asthma-Specific Data Collection Form}

\section{Patient Information}

Patient ID:

(Note: remember to keep an updated patient list and store in locked cabinet)

\section{Peak Flow Assessment}

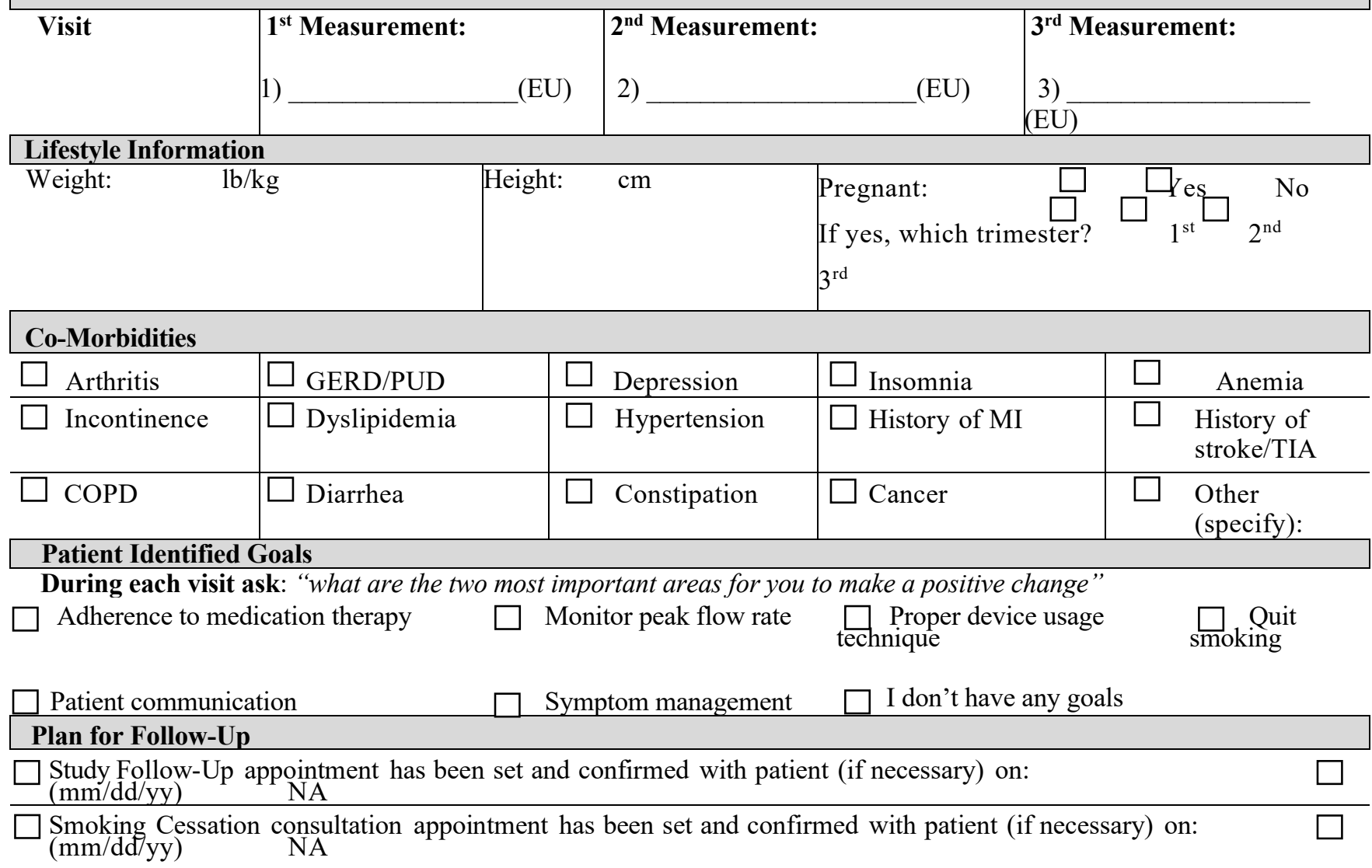

\section{Checklist for Completeness of Consultation (check all boxes that are applicable)} Checklist for Consultation

Discussed Rx medications, OTCs (including ASA), herbals and vitamins from other individuals/pharmacies/countries and MD samples

Prompted for specific dosage forms (i.e., inhalers, topicals, eye drops, nasal sprays, patches, injectables, etc.)

Referenced attached notes, results, references as appropriate

Discussed Follow up Appointments

Discussed proper use of peak flow meter

Discussed basic pathophysiology of asthma

Discussed proper use of inhaler

Discussed appropriate use of relievers (rescue medication) and controllers (preventative medications)

Discussed symptom management techniques

Provided a brochure for educational purposes (only to intervention group but if control asks then permitted)

Discussed smoking cessation drug therapies

Discussed non pharmacological options for smoking cessation

Discussed asthma action plan 
Discussed strategies for improving adherence

Checklist for Questionnaires and Handouts

Discussed monitoring of peak flow measurements using the Peak Flow Diary to be collected at each interim follow-up appointment

Distributed the following questionnaires, to be completed by the patient within one week of the baseline assessment and

collected at the $2^{\text {nd }}$ appointment.

Health Care Service Usage Questionnaire

$\square$ Asthma Control Questionnaire

The Medication Adherence Report Scale for Asthma

Asthma Quality of Life Questionnaire

Asthma General Knowledge Questionnaire for Adults

Heath and Work Performance Questionnaire

Asthma Self-Management Questionnaire

Acknowledgement and Privacy Notice

I agree to comply with all conditions laid out in the Personal Information Protection and Electronic Documents Act (PIPEDA), or provincial legislations that has been deemed to be substantially similar. I agree to comply with all conditions regarding privacy laid out in the Asthma Coaching Pulmonary training documents.

Signature of Pharmacist

Date:

By signing below, I agree to participate in the Pilot Test and Evaluation of a Community Pharmacist Managed Asthma Consultation Service and acknowledge that the service provided to me as described and in accordance with the service agreement. I understand that personal information collected will be used for the delivery of this coaching program. I understand that the research team may access this information for the purposes of auditor for the purposes of research. I understand that personal information collected will not be used for any other purpose by the research team.

\begin{tabular}{|l|l}
\hline Signature of Pharmacist & Date:
\end{tabular}

Pharmacists Notes

Duration of Appointment:

\begin{tabular}{l|l|l}
\hline Pharmacist name: & Pharmacist Signature: & Date:
\end{tabular} 


\section{Do you have Asthma? Are you taking a corticosteroid inhaler?}

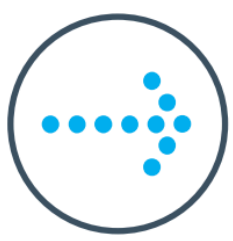

If so, you may be able to participate in a 12 month study looking at how pharmacists can help you manage your asthma. We are seeking approximately 100 participants to take part in up to 8 asthma consultation sessions with their pharmacists. At the first and last sessions, participants will be asked to complete several short questionnaires to assess whether this program has the potential to help other asthmatics.

\section{Ask your pharmacist how!}

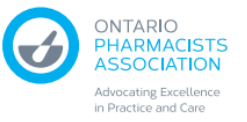




\section{References}

Johnbull J., Olayia, A.B. (2013). Assessment of asthma control using Asthma Control Test (ACT) and its relationship with lung function parameters. Greener Journal of Medical Sciences, 3(8), 276-282.

Enderlein, G. (1988). Fleiss, JL: The Design and Analysis of Clinical Experiments. Wiley, New York-Chichester-Brislane-Toronto-Singapore 1986, 432 S. £ 38.35.

Saini, B., Krass, I., \& Armour, C. (2004). Development, implementation, and evaluation of a community pharmacy-based asthma care model. Annals of Pharmacotherapy, 38(11), 1954-1960.

Armour, C., Bosnic-Anticevich, S., Brillant, M., Burton, D., Emmerton, L., Krass, I., ... \& Stewart, K. (2007). Pharmacy Asthma Care Program (PACP) improves outcomes for patients in the community. Thorax, 62(6), 496-592.

Ontario Lung Association. (2016). What is Asthma? Retrieved April 25, 2016, from http://www.on.lung.ca/page.aspx?pid=397

Ontario Pharmacists Association (2014). Impact of Community Pharmacist Interventions in Hypertension Management on Patient Outcomes : A Randomized Controlled Trial.

Asthma Society of Canada. (2015). Asthma facts and statistics FAQs. Retrieved from http://www.asthma.ca/adults/about/asthma_facts_and_statistics.pdf

Ministry of Health and Long-Term Care. (2010). New MedCheck Service Accessed. Retreived from https://news.ontario.ca/mohltc/en/2010/11/new-medscheck-services.html

Public Health Agency of Canada. (2007). Life and breath: respiratory disease in Canada.

Retrieved from: http://www.phac- aspc.gc.ca/publicat/2007/lbrdc-vsmrc/index-eng.php

Peters, S. P., Jones, C. A., Haselkorn, T., Mink, D. R., Valacer, D. J., \& Weiss, S. T. (2007). Realworld Evaluation of Asthma Control and Treatment (REACT): findings from a national Web-based survey. Journal of Allergy and Clinical Immunology, 119(6), 1454

National Institutes of Health. (1995). Global Initiative for Asthma. Global strategy for asthma management and prevention. NHLBI/WHO work shop report.

Zillich, A. J., Jaynes, H. A., Bex, S. D., Boldt, A. S., Walston, C. M., Ramsey, D. C., ... \& Bravata, D. M. (2015). Evaluation of pharmacist care for hypertension in the Veterans Affairs patient-centered medical home: a retrospective case-control study. The American journal of medicine, 128(5), 539-e1.

Santschi, V., Chiolero, A., Colosimo, A. L., Platt, R. W., Taffé, P., Burnier, M., ... \& Paradis, G. (2014). Improving blood pressure control through pharmacist interventions: a meta analysis of randomized controlled trials. Journal of the American Heart Association, 3(2), $\quad 0000718$. 
Machado, M., Bajcar, J., Guzzo, G. C., \& Einarson, T. R. (2007). Sensitivity of patient outcomes to pharmacist interventions. Part II: Systematic review and meta-analysis in hypertension management. Annals of Pharmacotherapy, 41(11), 1770-1781.

Rojas-Fernandez, C. H., Patel, T., \& Lee, L. (2014). An Interdisciplinary Memory Clinic A NovelPractice Setting for Pharmacists in Primary Care. Annals of Pharmacotherapy, 48(6), $\quad$ 785-795.

Simpson, S. H., Lier, D. A., Majumdar, S. R., Tsuyuki, R. T., Lewanczuk, R. Z., Spooner, R., \& Johnson, J. A. (2015). Cost-effectiveness analysis of adding pharmacists to primary care teams to reduce cardiovascular risk in patients with Type 2 diabetes: results from a randomized controlled trial. Diabetic Medicine, 32(7), 899-906.

Simpson, S. H., Majumdar, S. R., Tsuyuki, R. T., Lewanczuk, R. Z., Spooner, R., \& Johnson, J. A. (2011). Effect of Adding Pharmacists to Primary Care Teams on Blood Pressure Control in Patients With Type 2 Diabetes A randomized controlled trial. Diabetes Care, 34(1), 20-26.

Hepler, C. D., \& Strand, L. M. (1990). Opportunities and responsibilities in pharmaceutical care. Am J hosp pharm, 47(3), 533-543.

Canadian Pharmacists Association. (2008). Taskforce on a Blueprint for pharmacy: Blueprint for Pharmacy: The vision for pharmacy.

Ontario College of Pharmacists. (2013). Expanded scope of practice. Retrieved from: http://www.ocpinfo.com/Client/ocp/ocphome.nsf/web/Expanded+Scope+of+Practice

Expanding Professional Pharmacy Services Working Group. (2010). Report from the EPPS working group. Toronto (ON): EPPS working group

Juniper, E. F., O'BYRNE, P. M., Ferrie, P. J., King, D. R., \& Roberts, J. N. (2000). Measuring asthma control: clinic questionnaire or daily diary?. American journal of respiratory and critical care medicine, 162(4), 1330-1334.

Cohen, J. L., Mann, D. M., Wisnivesky, J. P., Horne, R., Leventhal, H., Musumeci-Szabó, T. J., \& Halm, E. A. (2009). Assessing the validity of self-reported medication adherence among inner-city asthmatic adults: the Medication Adherence Report Scale for Asthma. Annals of Allergy, Asthma \& Immunology, 103(4), 325-331.

Juniper, E. F., Guyatt, G. H., Feeny, D. H., Ferrie, P. J., Griffith, L. E., \& Townsend, M. (1996). Measuring quality of life in children with asthma. Quality of life research, 5(1), 35-46.

Juniper, E. F., Guyatt, G. H., Ferrie, P. J., \& King, D. R. (1999). Development and validation of a questionnaire to measure asthma control. European Respiratory Journal, 14(4), $902 \quad 907$.

Kessler, R. C., Barber, C., Beck, A., Berglund, P., Cleary, P. D., McKenas, D., ... \& Wang, P. (2003). The world health organization health and work performance questionnaire (HPQ). Journal of Occupational and Environmental Medicine, 45(2), 156-174.

Mancuso, C. A., Sayles, W., \& Allegrante, J. P. (2009). Development and testing of the asthma selfmanagement questionnaire. Annals of Allergy, Asthma \& Immunology, 102(4), $294 \quad 302$. 
Allen, R. M., \& Jones, M. P. (1998). The validity and reliability of an asthma knowledge questionnaire used in the evaluation of a group asthma education self-management program for adults with asthma. Journal of Asthma, 35(7), 537-545.

McLean, W. M., \& MacKeigan, L. D. (2005). When Does Pharmaceutical Care Impact Health Outcomes? A Comparison of Community Pharmacy_Based Studies of Pharmaceutical Care for Patients with Asthma. Annals of Pharmacotherapy, 39(4), 625-631.

McLean, W., Gillis, J., \& Waller, R. (2002). The BC Community Pharmacy Asthma Study: A study of clinical, economic and holistic outcomes influenced by an asthma care protocol provided by specially trained community pharmacists in British Columbia. Canadian respiratory journal: journal of the Canadian Thoracic Society, 10(4), 195-202.

Sadatsafavi, M., Lynd, L., Marra, C., Carleton, B., Tan, W. C., Sullivan, S., \& Mark FitzGerald, J. (2010). Direct health care costs associated with asthma in British Columbia. Canadian Respiratory Journal, 17(2), 74.

Schulz, M., Verheyen, F., Mühlig, S., Müller, J. M., Mühlbauer, K., Knop-Schneickert, E., ... \& Bergmann, K. C. (2001). Pharmaceutical care services for asthma patients: a controlled intervention study. The Journal of Clinical Pharmacology, 41(6), 668-676.

McLean, W., Gillis, J., \& Waller, R. (2002). The BC Community Pharmacy Asthma Study: A study of clinical, economic and holistic outcomes influenced by an asthma care protocol provided by specially trained community pharmacists in British Columbia. Canadian respiratory journal: journal of the Canadian Thoracic Society, 10(4), 195-202.

García-Cárdenas, V., Sabater-Hernández, D., Kenny, P., Martínez-Martínez, F., Faus, M. J., \& Benrimoj, S. I. (2013). Effect of a pharmacist intervention on asthma control. A cluster randomised trial. Respiratory medicine, 107(9), 1346-1355.

Barbanel, D., Eldridge, S., \& Griffiths, C. (2003). Can a self-management programme delivered by a community pharmacist improve asthma control? A randomised trial. Thorax, 58(10), 851-854.

Juniper, E. F., Guyatt, G. H., Ferrie, P. J., \& King, D. R. (1999). Development and validation of a questionnaire to measure asthma control. European Respiratory Journal, 14(4), $902 \quad-907$.

Legorreta, A. P., Christian-Herman, J., O'Connor, R. D., Hasan, M. M., Evans, R., \& Leung, K. M. (1998). Compliance with national asthma management guidelines and specialty care: a health maintenance organization experience. Archives of Internal Medicine, 158(5), 457-464.

Cote, J., Cartier, A., Malo, J. L., Rouleau, M., \& Boulet, L. P. (1998). Compliance with peak expiratory flow monitoring in home management of asthma. CHEST Journal, 113(4), 972.

To, T., Daly, C., Feldman, R., \& McLimont, S. (2012). Results from a community-based program evaluating the effect of changing smoking status on asthma symptom control. BMC public health, 12(1), 1.

Boulet, L. P., FitzGerald, J. M., McIvor, R. A., Zimmerman, S., \& Chapman, K. R. (2008). Influence of current or former smoking on asthma management and control. Canadian respiratory journal: journal of the Canadian Thoracic Society, 15(5), 275. 
Chaudhuri, R., Livingston, E., McMahon, A. D., Lafferty, J., Fraser, I., Spears, M., ... \& Thomson, N. C. (2006). Effects of smoking cessation on lung function and airway inflammation in smokers with asthma. American journal of respiratory and critical care medicine, 174(2), 127-133.

Ismaila, A. S., Sayani, A. P., Marin, M., \& Su, Z. (2013). Clinical, economic, and humanistic burden of asthma in Canada: a systematic review. BMC pulmonary medicine, 13(1), 1.

Castro, M., Zimmermann, N. A., Crocker, S., Bradley, J., Leven, C., \& Schechtman, K. B. (2003). Asthma intervention program prevents readmissions in high healthcare users. American Journal of Respiratory and Critical Care Medicine, 168(9), 1095-1099.

Shaw, J. P., Emmerton, L., Kheir, N. A., Barron, P. A., Becket, G., \& Smith, N. A. (2000). Pharmaceutical care of asthma patients in a New Zealand community pharmacy setting. Pharm J.. Available at URL: http://www. pjonline. com/Editorial/20000916/practiceresearch/r24.html.

Saini, B., LeMay, K., Emmerton, L., Krass, I., Smith, L., Bosnic-Anticevich, S., ... \& Armour, C. (2011). Asthma disease management-Australian pharmacists' interventions improve patients' asthma knowledge and this is sustained. Patient education and counseling, $\quad$ 83(3), 295-302.

Barthwal, M. S., Katoch, C. D. S., \& Marwah, V. (2009). Impact of optimal asthma education programme on asthma morbidity, inhalation technique and asthma knowledge. $J$ Assoc Physicians India, 57(574576), 579.

Närhi, U., Airaksinen, M., Tanskanen, P., \& Enlund, H. (2001). The effects of a pharmacy-based intervention on the knowledge and attitudes of asthma patients. Patient education and counseling, 43(2), 171-177.

Allen, R. M., \& Jones, M. P. (1998). The validity and reliability of an asthma knowledge questionnaire used in the evaluation of a group asthma education self-management program for adults with asthma. Journal of Asthma, 35(7), 537-545.

Mazor, K. M., Sabin, J. E., Boudreau, D., Goodman, M. J., Gurwitz, J. H., Herrinton, L. J., ... \& Platt, R. (2007). Cluster randomized trials: opportunities and barriers identified by leaders of eight health plans. Medical care, S29-S37.

Kaplan, B., \& Maxwell, J. A. (2005). Qualitative research methods for evaluating computer information systems. In Evaluating the organizational impact of healthcare information systems (pp. 30-55). Springer New York.

Atreja, A., Bellam, N., \& Levy, S. R. (2005). Strategies to enhance patient adherence: making it simple. Medscape General Medicine, 7(1), 4.

National Association of Pharmacy Regulatory Authorities. (2010). Model Standards of Practice for Canadian Pharmacists. Retrieved at: http://www.ocpinfo.com/Client/ocp/OCPHome.nsf/object/Model_Standards/\$file/Model_Standards.pdf

Shoukat, S., Gowani, S. A., Khowaja, A. A., \& Khan, J. (2009). Assessment of asthma control using the asthma control test at a tertiary care centre in Karachi, Pakistan. Journal of the Pakistan Medical Association, 59(3), 173. 
Enderlein, G. (1986). FleissJL The design and analysis of clinical experiments.

Saini, B., Krass, I., \& Armour, C. (2004). Development, implementation, and evaluation of a community pharmacy-based asthma care model. Annals of Pharmacotherapy, 38(11), 1954-

1960.

Armour, C., Bosnic-Anticevich, S., Brillant, M., Burton, D., Emmerton, L., Krass, I., ... \& Stewart, K. (2007). Pharmacy Asthma Care Program (PACP) improves outcomes for patients in the community. Thorax, 62(6), 496-592.

Norman K. Denzin, \& Yvonna S. Lincoln. (2005). The Sage handbook of qualitative research. $\quad$ Sage.

Braun, V., \& Clarke, V. (2006). Using thematic analysis in psychology. Qualitative research in psychology, 3(2), 77-101.

Mack, N., Woodsong, C., MacQueen, K. M., Guest, G., \& Namey, E. (2005). Qualitative research methods: a data collectors field guide.

Schulz, M., Verheyen, F., Mühlig, S., Müller, J. M., Mühlbauer, K., Knop-Schneickert, E., ... \& Bergmann, K. C. (2001). Pharmaceutical care services for asthma patients: a controlled intervention study. The Journal of Clinical Pharmacology, 41(6), 668-676.

Boulet, L. P., FitzGerald, J. M., McIvor, R. A., Zimmerman, S., \& Chapman, K. R. (2008). Influence of current or former smoking on asthma management and control. Canadian respiratory journal: journal of the Canadian Thoracic Society, 15(5), 275.

Giraud, V., Allaert, F. A., \& Roche, N. (2011). Inhaler technique and asthma: feasability and acceptability of training by pharmacists. Respiratory medicine, 105(12), 1815-1822.

Armour, C., Bosnic-Anticevich, S., Brillant, M., Burton, D., Emmerton, L., Krass, I., ... \& Stewart, K. (2007). Pharmacy Asthma Care Program (PACP) improves outcomes for patients in the community. Thorax, 62(6), 496-592.

Diamond, S. A., \& Chapman, K. R. (2000). The impact of a nationally coordinated pharmacy based asthma education intervention. Canadian respiratory journal: journal of the Canadian Thoracic Society, 8(4), 261-265.

Närhi, U., Airaksinen, M., Tanskanen, P., \& Enlund, H. (2001). The effects of a pharmacy-based intervention on the knowledge and attitudes of asthma patients. Patient education and counseling, 43(2), 171-177.

Hepler, C. D., \& Strand, L. M. (1990). Opportunities and responsibilities in pharmaceutical care. Am J hosp pharm, 47(3), 533-543.

Martin, M. A., Catrambone, C. D., Kee, R. A., Evans, A. T., Sharp, L. K., Lyttle, C., ... \& Chicago Initiative to Raise Asthma Health Equity Investigative Team. (2009). Improving asthma selfefficacy: developing and testing a pilot community-based asthma intervention for African American adults. Journal of Allergy and Clinical Immunology, 123(1), 153-159. 
Shaw, J. P., Emmerton, L., Kheir, N. A., Barron, P. A., Becket, G., \& Smith, N. A. (2000).

Pharmaceutical care of asthma patients in a New Zealand community pharmacy setting. Pharm J.. Available at URL: http://www.pjonline. com/Editorial/20000916/practiceresearch/r24. html.

Ontario College of Pharmacists. Expanded scope of practice. 2013. Available from: http://www.ocpinfo.com/Client/ocp/ocphome.nsf/web/Expanded+Scope+of+Practice

Expanding Professional Pharmacy Services Working Group. Report from the EPPS working group. Toronto (ON): EPPS working group; 2010.

McLean, W. M., \& MacKeigan, L. D. (2005). When Does Pharmaceutical Care Impact Health Outcomes? A Comparison of Community Pharmacy - Based Studies of Pharmaceutical Care for Patients with Asthma. Annals of Pharmacotherapy, 39(4), 625-631.

Mehuys, E., Van Bortel, L., De Bolle, L., Van Tongelen, I., Annemans, L., Remon, J. P., \&

Brusselle, G. (2008). Effectiveness of pharmacist intervention for asthma control improvement. European Respiratory Journal, 31(4), 790-799.

Ismaila, A. S., Sayani, A. P., Marin, M., \& Su, Z. (2013). Clinical, economic, and humanistic $\quad$ burden of asthma in Canada: a systematic review. BMC pulmonary medicine, 13(1), 1.

Canadian Pharmacists Association. (2008). Taskforce on a Blueprint for pharmacy: Blueprint for Pharmacy: The vision for pharmacy.. Available at: http://www.pharmacists.ca/content/about_cpha/whats_happening/cpha_in_action/pdf/B ueprintVision.pdf

Barbanel, D., Eldridge, S., \& Griffiths, C. (2003). Can a self-management programme delivered by a community pharmacist improve asthma control? A randomised trial. Thorax, 58(10), 851-854.

Carrión, V. F., Maya, M. M., Fontana, S. I., Díaz, L. J., \& Marín, P. J. (2000). [Inhalation technique in patients with chronic respiratory diseases]. Archivos de bronconeumologia, $36(5), 236-240$.

Girodet, P. O., Raherison, C., Abouelfath, A., Lignot, S., Depont, F., Moore, N., \& Molimard, M. (2002). [Real-life use of inhaler devices for chronic obstructive pulmonary disease in primary care]. Therapie, $58(6), 499-504$.

Larsen, J. S., Hahn, M., Ekholm, B., \& Wick, K. A. (1994). Evaluation of conventional press-and breathe metered-dose inhaler technique in 501 patients. Journal of Asthma, 31(3), 193199.

Molimard, M., Raherison, C., Lignot, S., Depont, F., Abouelfath, A., \& Moore, N. (2003).

Assessment of handling of inhaler devices in real life: an observational study in 3811 patients in primary care. Journal of aerosol medicine, 16(3), 249-254.

Hamdan, A. L., Ahmed, A., Abdullah, A. L., Khan, M., Baharoon, S., Salih, S. B., ... \& Al Muhsen, S. (2013). Improper inhaler technique is associated with poor asthma control and frequent emergency department visits. Allergy Asthma Clin. Immunol, 9(1), 8.

Legorreta, A. P., Christian-Herman, J., O'Connor, R. D., Hasan, M. M., Evans, R., \& Leung, K. M. (1998). Compliance with national asthma management guidelines and specialty care: a health maintenance organization experience. Archives of Internal Medicine, 158(5), 457-464. 
Willems, D. C., Joore, M. A., Hendriks, J. J., Wouters, E. F., \& Severens, J. L. (2006). Cost effectiveness of self-management in asthma: a systematic review of peak flow monitoring interventions. International journal of technology assessment in health care, $\quad 22(4), 436-442$.

Martin, M. L., Patrick, D. L., Bushnell, D. M., Meltzer, E. O., Gutierrez, B., \& Parasuraman, B. (2009). Development of the asthma treatment satisfaction measure. Current medical research and opinion, 25(10), 2495-2506.

Knoell, D. L., Pierson, J. E., Marsh, C. B., Allen, J. N., \& Pathak, D. S. (1998). Measurement of outcomes in adults receiving pharmaceutical care in a comprehensive asthma outpatient clinic.

Pharmacotherapy: The Journal of Human Pharmacology and Drug Therapy, $\quad$ 18(6), 1365-1374.

Finkelstein, J. (2017). Machine learning approaches to personalize early prediction of asthma exacerbations. Annals of the New York Academy of Sciences, 1387(1), 153-165.

Reddel, H., Ware, S., Marks, G., Salome, C., Jenkins, C., \& Woolcock, A. (1999). Differences between asthma exacerbations and poor asthma control. The Lancet, 353(9150), 364

Reddel, H., Jenkins, C., \& Woolcock, A. (1999). Diurnal variability-time to change asthma guidelines?. BMJ: British Medical Journal, 319(7201), 45.

Cross, D., \& Nelson, H. S. (1991). The role of the peak flow meter in the diagnosis and management of asthma. Journal of allergy and clinical immunology, 87(1), 120-128.

Jamison, J. P., \& McKinley, R. K. (1993). Validity of peak expiratory flow rate variability for the diagnosis of asthma. Clinical science (London, England: 1979), 85(3), 367-371.

Aggarwal, A. N., Gupta, D., Chaganti, S., \& Jindal, S. K. (2000). Diurnal variation in peak expiratory flow in healthy young adults. INDIAN JOURNAL OF CHEST DISEASES AND ALLIED SCIENCES, 42(1), 15-20.

Knobloch, J. (2013). The effect of regular peak flow meter utilisation on asthma self management.

Pierce, R., \& Johns, D. (1995). The measurement and interpretation of ventilatory function in clinical practice. Australia: National Library of Australia.

Van der Palen, J., Klein, J. J., \& Seydel, E. R. (1997). Are high generalised and asthma-specific selfefficacy predictive of adequate self-management behaviour among adult asthma patients?. Patient education and counseling, 32, S35-S41.

Ramsdale, E. H., Morris, M. M., \& Hargreave, F. E. (1986). Interpretation of the variability of peak flow rates in chronic bronchitis. Thorax, 41(10), 771-776.

Center, A. R. (2013). Fernando D Martinez, Donata Vercelli. Lancet, 382, 1360-72.

Foster, J. M., Sawyer, S. M., Smith, L., Reddel, H. K., \& Usherwood, T. (2015). Barriers and facilitators to patient recruitment to a cluster randomized controlled trial in primary care: lessons for future trials. BMC medical research methodology, 15(1), 18. 
Thompson, K., Kulkarni, J., \& Sergejew, A. A. (2000). Reliability and validity of a new Medication Adherence Rating Scale (MARS) for the psychoses. Schizophrenia research, 42(3), 241-247.

MacCallum, L., Consiglio, G., MacKeigan, L., \& Dolovich, L. (2017). Uptake of community pharmacist-delivered MedsCheck diabetes medication review service in Ontario between 2010 and 2014. Canadian journal of diabetes, 41(3), 253-258.

Lee, V., Emberly, P. (2012). Winter 2012. Canadian Pharmacists Association The Translator, $6(1), 3$.

Hermus, G. (2012). Cost risk analysis for chronic lung disease in Canada. Conference Board of Canada.

Lemmens, K. M., Nieboer, A. P., \& Huijsman, R. (2009). A systematic review of integrated use of disease- management interventions in asthma and COPD. Respiratory medicine, 103(5), 670-691

Sturgess, I. K., McElnay, J. C., Hughes, C. M., \& Crealey, G. (2003). Community pharmacy based provision of pharmaceutical care to older patients. Pharmacy World and Science, 25(5), 218-226. 